\title{
Title: Starch replacement in gluten free bread by cellulose and fibrillated cellulose
}

Author names and affiliations:

Yi Ren ${ }^{1}$ yi.ren@nottingham.ac.uk +44(0)1159516012

Bruce R. Linter²Bruce.Linter@pepsico.com

Tim J. Foster ${ }^{1}$ Tim.Foster@nottingham.ac.uk

${ }^{1}$ Division of Food Sciences, School of Biosciences, University of Nottingham, Sutton Bonington Campus, Loughborough, LE12 5RD, UK

${ }^{2}$ PepsiCo International Ltd, 4 Leycroft Rd, Leicester, LE4 1ET, UK

Highlights:

- The incorporation of (fibrillated) cellulose strengthened gluten free doughs

- The generalised Maxwell model was applied to analyse dough rheology

- The incorporation of (fibrillated)cellulose influenced the later stage of proofing

- Volume and water competition dominates the thermal rheological behaviours

- Loaves with (fibrillated)cellulose were smaller with harder, denser but finer crumb

Keywords:

Fibrillated cellulose, cellulose, gluten free bread, dough rheology, bread quality 


\begin{abstract}
This study investigated starch reduction and replacement by purified cellulose (FC0) and fibrillated cellulose (FC60) which included a comprehensive investigation on dough properties, proofing behaviours, cooking performance, and bread qualities. Replacing flour with FC0 and FC60 was found to strength the doughs without, however, altering the extension of the structural network according to the weak gel model. The relaxation time calculated by the generalised Maxwell model was found to be shorter than the deformation rate during proofing which suggests that the doughs behave like fluids during proofing. The relaxation time was less influenced by the additions of FC0 and FC60. Although the initial stage of proofing was less influenced, the later stage was significantly affected by the additions of FC0 and FC60 which increased dough rigidity and restrained the volume growth. The pasting properties were significantly influenced by the competition for water and volume between FC0/FC60 and flour. The bread qualities were characterised in terms of loaf volume and crumb properties. Loaves containing FC0 and FC60 had smaller specific volume and harder crumb. However, the addition of FC0 and FC60 is beneficial to the generation of a finer crumb structure. Fibrillation process is detrimental to maximise the addition of fibres. However, a small amount of fibrillated cellulose is beneficial to workability and crumb structure.
\end{abstract}




\section{Introduction}

2 Wheat flour is the main ingredient of bread, the staple food in many regions. However, many 3 people around the world are intolerant or sensitive to gluten, which leads to coeliac disease and other gluten-trigged health problems (Catassi et al., 2012; Czaja-Bulsa, 2015; Sapone et al., 2012). In 2014, Aziz et al. (2014) conducted a survey in Sheffield, UK, and found that $13 \%$ of the population reported gluten sensitivity and the prevalence of diagnosed Celiac disease was $0.8 \%$. An early study reported that the prevalence of the coeliac disease in the world is approximately 1 in every 100 people (Zandonadi, Botelho \& Araujo, 2009). Celiac disease, the most widely studied gluten-triggered disease, is an autoimmune genetically determined chronic inflammatory intestinal disorder (Fasano \& Catassi, 2001; Schuppan, 2000) which can be influenced by both genetic (intrinsic) and environmental (extrinsic) factors (Di Sabatino \& Corazza, 2009; Schuppan, 2000; Wahab, Meijer, Goerres \& Mulder, 2002). On the other hand, 'free from' is becoming a global trend of a healthy lifestyle choice, which further promotes the market of gluten free products. The production and improvement of gluten free bread have been widely studied and the current methodologies can be categorised as the application of alternative flour blends, enzyme treatments and sourdough applications, and other treatments. The application of alternative flour blends is the most investigated which includes investigations on formulations (Haque \& Morris, 1994; Lazaridou, Duta, Papageorgiou, Belc \& Biliaderis, 2007; Nishita, Roberts, Bean \& Kennedy, 1976; Ronda, Pérez-Quirce, Angioloni \& Collar, 2013) and structured gel and colloids (Van Riemsdijk, van der Goot, Hamer \& Boom, 2011). Both dough rheological properties and bread qualities have been widely investigated. In addition, the development of the dough microstructure and during baking, which can be influential in the production of bread and other bakery goods, have also been studied (Babin et al., 2006; Baldino, Laitano, Lupi, Curcio \& Gabriele, 2018; Bousquières, Michon \& Bonazzi, 2017; Wagner, Quellec, Trystram \& Lucas, 2008).

In addition, the proportion of overweight adults and children has increased around the world and obesity has become a global health challenge during the past three decades ( $\mathrm{Ng}$ et al., 2014). The prevalence of obesity around the world is one of the main reasons for the increased morbidity rate of type-2 diabetes (Shaw, Sicree \& Zimmet, 2010). However, the removal of gluten from the diet easily lead to a significant decrease in carbohydrate oxidation rate, increase in body fat stores, and weight gain in celiac patients (Capristo et al., 2000; Hager et al., 2012). 
Therefore, food containing low calories and/or glycaemic index is recommended and the production of gluten-free bread with low-calorie content and glycaemic index will be beneficial to deal with gluten intolerance, obesity and type 2 diabetes simultaneously. The additions of dietary fibres or fibre enriched materials, most by-product or cell wall materials, have been studied to improve the nutritional profiles of gluten free bread. Demirkesen, Mert, Sumnu and Sahin (2010) produced gluten free bread with desirable qualities in terms of loaves, texture, colour and sensory perception by adding an intermediate amount of chestnut flour. Gluten free bread with enhanced fibre contents was achieved by incorporating apple fibres and sugar beet fibres with hydroxypropyl methylcellulose (HPMC) (Djordjevic et al., 2019). The addition of rice bran in gluten free bread has been investigated by Phimolsiripol, Mukprasirt and Schoenlechner (2012). The investigations on the addition of fibres were mainly based on the materials with a defined processing procedure or commercial products but the influence of fibre treatment, such as fibrillation, is less understood.

The fibres added in the bread formulation can be enriched in cellulose, hemicellulose, and/or pectin. These materials, either soluble or insoluble, usually have high water absorbability which significantly alters the rheological properties of doughs. The insoluble cellulose enriched materials can also be expected to play a role as fillers.

Cellulose is one of the main components in the plant cell wall, which structures, with hemicellulose, pectin, and lignin, to maintain the mechanical property of cell walls. Microfibrillated cellulose (MFC) was first processed using high pressure and shearing by Herrick, Casebier, Hamilton and Sandberg (1983) and Turbak, Snyder and Sandberg (1983a), where the native cellulose fibres are physically unwound and highly entangled cellulose fibrils are generated with high surface area, liquid retention, and reactivity to chemical treatments. In food productions, MFC can be used as a thickener, compound carriers, and suspension \& emulsion stabilisers (Turbak, Snyder \& Sandberg, 1982, 1983b). Currently, the applications of high pressure homogeniser and microfluidiser as mechanical cellulose fibrillation treatments are widely investigated to produce MFC (López-Rubio et al., 2007; Nakagaito \& Yano, 2004; Pääkkö et al., 2007; Stenstad, Andresen, Tanem \& Stenius, 2008; Zimmermann, Pöhler \& 60 Geiger, 2004). In this study, a colloid mill was used which has lower energy input. Therefore, the cellulose 62 was fibrillated to a less extend comparing to the production of MFC. The water absorbability 2 
and fibre configuration and rigidity were greatly altered by the fibrillation process. The aim of this study was to investigate the starch/flour reduction of rice flour based gluten free bread by the addition of cellulose and fibrillated cellulose. A high replacement level of up to $20 \%$ was included in the investigation. Dough properties, proofing behaviours, cooking performance, and bread qualities were of the interests to achieve a comprehensive understanding.

\section{Materials and methods}

\subsection{Materials}

Rice flour was purchased from Doves Farm online store. Allinson Easy Bake Yeast (Allinson Flour, Peterborough, UK), sugar (Sainsbury's, UK), sunflower oil (Sainsbury's, UK), and salt (Sainsbury's, UK) were purchased from local supermarkets. Methylcellulose (Methocel ${ }^{\circledR}$ A4M) was supplied by The Dow Chemical Company (Bomlitz, Germany). Vitacel ${ }^{\circledR}$ Psyllium seed husk powder was kindly donated by the JRS (J. Rettenmaier \& Söhne Group, Rosenberg, Germany). Pure amylose from potato and amylopectin from corn were purchased from SigmaAldrich (Dorset, UK). Pure powdered cellulose, Solka floc 900FCC, was supplied by International Fiber Corporation, US.

\subsection{Biochemical analysis}

Nitrogen content was measured using a Nitrogen Analyser NA 2000 (Fisons Scientific

80 Equipment, Loughborough, UK) and the protein contents of rice flour and psyllium seed husk powder were converted with a factor of 6.25. Lipid was extracted with a chloroform-methanol mixture (2:1) and the contents were calculated. Moisture contents were obtained by drying at $105^{\circ} \mathrm{C}$ and ash contents were measured using a muffle furnace at $550^{\circ} \mathrm{C}$.

AACC method (61-03) and the method from Kaufman, Wilson, Bean, Herald and Shi (2015) were modified to determine the amylose content of rice flour. Rice flour was defatted using $85 \%$ methanol. Defatted rice flour, potato amylose and corn amylopectin (100 mg) were dispersed in $1 \mathrm{ml}$ of $95 \%$ ethanol and then dissolved in $9 \mathrm{ml}$ of $1 \mathrm{M} \mathrm{NaOH}$ in a boiling water bath for $10 \mathrm{~min}$. After standing at room temperature for $3 \mathrm{~h}$, the starch solutions were diluted to $100 \mathrm{ml}$. The standard curve was obtained from mixtures of potato amylose and corn amylopectin in a series of different ratios. Samples $(5 \mathrm{ml})$ were diluted by 20 times with 
were incubated at room temperature for $20 \mathrm{~min}$. The absorbance at $720 \mathrm{~nm}$ was determined using a spectrophotometer. The amylose contents were calculated against the regression equation determined from the standard curve and verified by a standard starch sample with $66 \%$ amylose content.

\subsection{Cellulose fibrillation}

Five grams of cellulose was dispersed in $500 \mathrm{ml}$ of reverse osmosis (RO) water and fibrillated by a colloid mill (Winkworth, Basingstoke, UK) for 30 minutes $\left(60 \mathrm{~min} \mathrm{~L}^{-1}\right)$ and labelled as FC60. The fibrillated cellulose was then centrifuged at $4000 \mathrm{~g}, 4{ }^{\circ} \mathrm{C}$, for $15 \mathrm{~min}$ and the supernatants (residue less than $0.01 \%$ ) were discarded. The concentration of sediments was verified by drying at $105^{\circ} \mathrm{C}$ for each batch and stored at $4{ }^{\circ} \mathrm{C}$, which were then diluted to the required concentrations for dough preparations.

Table 1. Addition levels of rice flour, FC0, and FC60.

\begin{tabular}{|lccc|}
\hline Sample code & Rice flour & FC0 & FC60 \\
\hline F(100) (control) & 100 & 0 & 0 \\
F(98)+FC60(2) & 98 & 0 & 2 \\
F(90)+FC0 $(10)$ & 90 & 10 & 0 \\
F(90)+FC0 $(8)+F C 60(2)$ & 90 & 8 & 2 \\
F(80)+FC0(20) & 80 & 20 & 0 \\
F(80)+FC0(18)+FC60(2) & 80 & 18 & 2 \\
F(80)+FC0(16)+FC60(4) & 80 & 16 & 4 \\
\hline
\end{tabular}

\subsection{Dough formulation and preparation}

The basic formulation (control) was decided according to preliminary tests and included $100 \mathrm{~g}$ of rice flour, $5 \mathrm{~g}$ of sugar, $2 \mathrm{~g}$ of salt, $1.5 \mathrm{~g}$ of yeast, $5 \mathrm{~g}$ of vegetable oil, $1 \mathrm{~g}$ of methylcellulose (MC), $1 \mathrm{~g}$ of psyllium, and $120 \mathrm{~g}$ of water. Rice flour was partially replaced with pure cellulose powder (FC0) and/or fibrillated cellulose (FC60) as shown in Table 1. Apart from F(100) (control) and $\mathrm{F}(98)+\mathrm{FC} 60(2)$, all other $\mathrm{FC} 0 / \mathrm{FC} 60$ incorporated formulas are expected to be claimed 'high fibre' according to Regulation (EC) No 1924/2006 based on a rough calculation that the fibre content is higher than $3 \mathrm{~g}$ per $100 \mathrm{kcal}$. FC0 was directed used to replace rice flour and mixed with other dry ingredients. FC60 was redispersed in water required in the formulation and added with oil into dry ingredients. Doughs were mixed based on $200 \mathrm{~g}$ of rice flour or the mixture of flour and cellulose per batch by a stand mixer (Kenwood, UK) equipped 
116 with a CHEF flexible beater (AT501, Kenwood, Havant, UK). Dry ingredients were mixed

117 thoroughly and then mixed with water/FC60 dispersion and oil for $7 \mathrm{~min}$ at speed 1. Doughs

118 prepared for rheological measurements did not contain yeast and were allowed for hydration

119 at room temperature for 1 hour.

120 2.5. Dough evaluation

$121 \quad$ 2.5.1. Fundamental rheological measurements and thermal behaviour of doughs

122 Doughs without yeast, which were hydrated for 1 hour at room temperature, were subjected to 123 shear stress ramp tests and small amplitude oscillatory shear tests by MRC 301 rheometer 124 (Anton Paar, Austria) equipped with serrated parallel plate geometry (PP25/P2-SN15766, 125 Anton Paar). The measuring gap was $2 \mathrm{~mm}$. The temperature was controlled by a Peltier system 126 with the assistance of a water bath (R1, Grant, Shepreth, UK). The extra sample was trimmed 127 by a spatula during sample loading and the edge was covered by low viscosity mineral oil 128 (Sigma, USA) to prevent drying. Doughs rested at $30^{\circ} \mathrm{C}$ for 500 seconds before measurements. 129 Logarithmic increase of shear stress from 0.03 to $30000 \mathrm{~Pa}$ in $18.5 \mathrm{~min}$ was performed to obtain 130 the yield point or yield zone. Frequency sweep tests were performed in a logarithmic decrease 131 from 600 to $0.06 \mathrm{rad} \mathrm{s}^{-1}$ with $0.02 \%$ strain (in the linear viscoelastic region). The slopes of $\lg \mathrm{G}^{\prime}$ 132 versus $\lg \omega$ in the middle frequency range $\left(0.881\right.$ to $\left.40.9 \mathrm{~s}^{-1}\right)$ were calculated. The dynamic 133 oscillatory measurement data were also fitted into the 'weak gel' model (equation 1) proposed 134 by Gabriele, de Cindio and D'Antona (2001) where $\mathrm{z}$ represents the number of the interacting 135 rheological units of 'weak gel' structure and A refers to the interaction strength between the 136 rheological units. $G^{*}(\omega)$ is the complex modulus.

$$
G^{*}(\omega)=\pi A \omega^{\frac{1}{z}}
$$

138 Additionally, the obtained mechanical spectra were fitted to generalised Maxwell model as 139 shown in equation (2) with individual relaxation time $\left(\lambda_{\mathrm{i}}\right)$ and individual relaxation moduli $\left(G_{\mathrm{i}}\right)$ 140 describing the discrete relaxation time spectrum of the sample where $G(t)$ is the relaxation 141 modulus at time t.

$$
G(t)=\sum_{i=1}^{N} G_{i} e^{-t / \lambda_{i}}
$$


143 The relaxation times of each component $\left(\lambda_{\mathrm{i}}\right)$ were arbitrarily decided as shown in Table 2 . The

144 dynamic moduli $G^{\prime}(\omega)$ and $G^{\prime} '(\omega)$ were calculated from angular frequency ( $\left.\omega\right)$ by equation (3)

145 and (4) (Baumgaertel \& Winter, 1992; Ferry, 1980; Laun, 1986). Individual relaxation moduli

$146 G_{\mathrm{i}}$, which is listed in Table 2, was varied to minimise the sum of square differences between

147 calculated $G^{\prime}(\omega), G^{\prime}$ ' $(\omega)$ and experimentally obtained G', G', Ge represents a pure elastic

148 component connected in parallel with other Maxwell elements in the model.

$$
G^{\prime}(\omega)=\sum_{i} G_{i} \frac{\omega^{2} \lambda_{i}^{2}}{1+\omega^{2} \lambda_{i}^{2}}+G_{e}
$$

150

$$
G^{\prime \prime}(\omega)=\sum_{i} G_{i} \frac{\omega \lambda_{i}}{1+\omega^{2} \lambda_{i}^{2}}
$$

151 Temperature sweep tests were performed at a constant strain $(0.02 \%)$ and angular frequency

$152\left(10 \mathrm{rad} \mathrm{s}^{-1}\right)$ with the temperature increased from $20^{\circ} \mathrm{C}$ to $98{ }^{\circ} \mathrm{C}$ with a heating rate of $2.6^{\circ} \mathrm{C}$

$153 \min ^{-1}$ mimicking the temperature profile during baking.

154 Table 2. Individual relaxation time and relaxation moduli for Generalised Maxwell Model fitting on the

\begin{tabular}{|c|c|c|c|c|c|c|c|c|c|c|c|}
\hline $\begin{array}{c}\text { individual } \\
\text { relaxation time } \\
\lambda_{\mathrm{i}}(\mathrm{s})\end{array}$ & 0.0001 & 0.001 & 0.01 & 0.1 & 1 & 10 & 100 & 1000 & 10000 & 100000 & $\mathrm{R}^{2}$ \\
\hline $\mathrm{F}(100)$ (control) & 123755 & 0 & 1201 & 1146 & 724 & 1934 & 1237 & 0 & 0.010 & 0.001 & 0.991 \\
\hline $\mathrm{F}(98)+\mathrm{FC} 60(2)$ & 0 & 14804 & 6066 & 3950 & 3113 & 1925 & 8856 & 0 & 0.012 & 0.001 & 0.996 \\
\hline $\mathrm{F}(90)+\mathrm{FC} 0(10)$ & 255156 & 0 & 3575 & 3270 & 2264 & 6034 & 3748 & 0 & 0.011 & 0.001 & 0.989 \\
\hline $\begin{array}{c}\mathrm{F}(90)+\mathrm{FC} 0(8)+ \\
\mathrm{FC} 60(2)\end{array}$ & 279077 & 0 & 5451 & 6761 & 3917 & 11764 & 6455 & 0 & 0.013 & 0.002 & 0.980 \\
\hline $\mathrm{F}(80)+\mathrm{FC} 0(20)$ & 354470 & 18597 & 23156 & 18045 & 12357 & 22615 & 25966 & 0 & 0.010 & 0.002 & 0.998 \\
\hline $\begin{array}{c}\mathrm{F}(80)+\mathrm{FC} 0(18) \\
+\mathrm{FC} 60(2)\end{array}$ & 904692 & 0 & 31077 & 29132 & 18275 & 37525 & 42383 & 0 & 0.010 & 0.000 & 0.994 \\
\hline $\begin{array}{c}\mathrm{F}(80)+\mathrm{FC} 0(16) \\
+\mathrm{FC} 60(4)\end{array}$ & 1271 & 88716 & 36796 & 29398 & 18524 & 32671 & 47364 & 0 & 0.010 & 0.017 & 0.998 \\
\hline
\end{tabular}
155 mechanical spectra shown in Figure 2.

\section{$156 \quad$ 2.5.2. Empirical rheological measurements}

157 Doughs were also characterised on a TA-XT plus texture analyser (Stable Micro systems,

158 Surrey, UK) equipped with a $5 \mathrm{~kg}$ loading cell. Backward extrusion tests and SMS/Chen159 Hoseney Dough Stickiness tests (Stable Micro Systems, UK) were performed. For the 
160 backward extrusion tests, doughs were loaded into a container with a diameter of $42 \mathrm{~mm}$ to a 161 height of $36 \mathrm{~mm}$ avoiding big air pockets. A disc with a diameter of $30 \mathrm{~mm}$ and thickness of 5 $\mathrm{mm}$ was centred and extruded into the dough by $22.5 \mathrm{~mm}$ and then returned to the height of $120 \mathrm{~mm}$ from the base at a speed of $1 \mathrm{~mm} \mathrm{~s}^{-1}$. The positive peak force and positive area during downward stroke indicated firmness and consistency of doughs respectively. The negative peak force and area during upward stroke indicated cohesiveness and index of viscosity. The returning distance before the force reached a constant negative value indicated dough extensibility. As for the SMS/Chen-Hoseney Dough Stickiness tests (Chen \& Hoseney, 1995), doughs were loaded into the equipped cell (A/DSC) and a uniform surface was generated. The surface was compressed by an aluminium cylinder probe $(\mathrm{P} / 25)$ by $40 \mathrm{~g}$ for $0.1 \mathrm{~s}$. The probe compressed the sample at the speed of $0.5 \mathrm{~mm} \mathrm{~s}^{-1}$ and withdrew at $10 \mathrm{~mm} \mathrm{~s}^{-1}$. The maximum force, area, and travel distance during probe withdrawing indicated dough stickiness, work of adhesion, and strength individually. Data recording and analysis were performed by the equipped software Exponent 6.1.14.

\subsection{Pasting properties of flour blends}

175 The pasting profiles of flour blends were measured by Rapid Visco Analyser (RVA) (Newport

176 Scientific Pty. Ltd., Warriewood, New South Wales, Australia) equipped with a water bath 177 (Thermo scientific C10, Karlsruhe, Germany). The solid levels of rice flour, MC, psyllium, 178 FC0, and FC60 are listed in Table 3, which were in the same ratio as in the dough formulation 179 without sugar, salt, yeast, and oil. More specifically, flour, MC, psyllium and FC0 were mixed 180 thoroughly. Flour blends (2.55 g) prepared according to the formula which does not include 181 FC60 were dispersed in $24 \mathrm{ml}$ of RO water. As for FC60-containing formula, FC60 stock 182 suspensions were diluted to $24.05 \mathrm{~g}$ or $24.1 \mathrm{~g}$ with FC60 concentration of $0.208 \%$ and $0.415 \%$ 183 respectively for the formulations of $2 \%$ and $4 \%$ replacement by FC60. Flour blends (2.5 or 1842.45 g respectively) were dispersed into diluted FC60 suspensions. The test started with high 185 shear rate mixing $(960 \mathrm{rpm})$ for 60 seconds at $25^{\circ} \mathrm{C}$ followed by 60 seconds mixing at 160 $186 \mathrm{rpm}$. The temperature then increased to $95{ }^{\circ} \mathrm{C}$ in $350 \mathrm{~s}$, held at $95{ }^{\circ} \mathrm{C}$ for $150 \mathrm{~s}$, and decreased 187 to $25{ }^{\circ} \mathrm{C}$ in $350 \mathrm{~s}$. The pasting profiles were analysed by Thermocline where pasting 188 temperature (the temperature of the onset of viscosity increase), peak (the highest viscosity), 189 peak time (the time when the highest viscosity was reached), trough (lowest viscosity after the 190 peak), trough time (the time when the trough occurred), final viscosity, breakdown (difference 
191 between peak and trough), and setback (difference between final viscosity and trough viscosity) were reported.

193 Table 3. Addition levels of rice flour, MC, psyllium, FC0, and FC60 in pasting property analysis.

\begin{tabular}{|l|cccccc|}
\hline Sample code & $\begin{array}{c}\text { Rice } \\
\text { flour }\end{array}$ & MC & psyllium & FC0 & $\begin{array}{c}\text { total dry } \\
\text { blends }\end{array}$ & FC60 \\
\hline F(100) (control) & 2.5 & 0.025 & 0.025 & 0 & 2.55 & 0 \\
F(98)+FC60(2) & 2.45 & 0.025 & 0.025 & 0 & 2.5 & 0.05 \\
F(90)+FC0(10) & 2.25 & 0.025 & 0.025 & 0.25 & 2.55 & 0 \\
F(90)+FC0(8)+FC60(2) & 2.25 & 0.025 & 0.025 & 0.2 & 2.5 & 0.05 \\
F(80)+FC0(20) & 2 & 0.025 & 0.025 & 0.5 & 2.55 & 0 \\
F(80)+FC0(18)+FC60(2) & 2 & 0.025 & 0.025 & 0.45 & 2.5 & 0.05 \\
F(80)+FC0(16)+FC60(4) & 2 & 0.025 & 0.025 & 0.4 & 2.45 & 0.1 \\
\hline
\end{tabular}

\subsection{Baking tests}

196 Doughs prepared according to section 2.3 were loaded in a baking pan with a dimension of 7.5

$197 \times 7.5 \times 10 \mathrm{~cm}(\mathrm{~W} \times \mathrm{L} \times \mathrm{H})$. Each batch generated two doughs with weights of 200 to $210 \mathrm{~g}$.

198 Baking pan was shaken to expel big air pockets in doughs. The doughs were covered by cling 199 film and proofed in an incubator (Binder, Tuttlingen, Germany) at $30^{\circ} \mathrm{C}$ for 85 min and then 200 baked in a deck oven (Tom Chandley, Manchester, UK) for $40 \mathrm{~min}$ at $230^{\circ} \mathrm{C}$. The loaves were 201 cooled on a rack at the atmosphere environment for 1 hour before further evaluation.

\subsubsection{Basic analysis and calculations}

203 Proofing behaviour was monitored by incubating approximately $10 \mathrm{ml}$ of doughs in a measuring 204 cylinder at $30^{\circ} \mathrm{C}$ for 85 min during which the volume was recorded. Doughs were weighted 205 before baking and the loaves were weighted after baking and cooling. Loaf volumes were 206 measured by rapeseed replacement. The baking loss was calculated by baking loss = 207 (dough weight before proving - loaf weight after cooling)/dough weight before proving.

208 Specific volume was the ratio of loaf volume to loaf weight. The moisture content of the loaf centre 209 was measured by drying a piece of crumb cut from the centre at $105^{\circ} \mathrm{C}$.

210 The loaves were sliced perpendicularly to a thickness of $1.25 \mathrm{~cm}$ and the middle surface was 211 scanned using a C-Cell imaging system (Calibre Control International LTD, Warrington, UK).

212 The obtained imaged were analysed using C-Cell software version 2.0.

\section{$213 \quad$ 2.7.2. Bread textural evaluation}


214 The textural property of gluten free bread was evaluated by texture profile analysis (TPA) on

215 a TA-XT plus texture analyser (Stable Micro systems, Surrey, UK) equipped with $30 \mathrm{~kg}$

216 loading cell. A cylinder piece of bread crumb was cut from the centre of every loaf slice by a

217 diameter of $3 \mathrm{~cm}$ and two pieces from the middle four slices of each loaf were stacked together.

218 Therefore, two pieces of the sample were obtained from the middle of each loaf with the shape

219 of a cylinder with a height and a diameter of $2.5 \mathrm{~cm}$ and $3 \mathrm{~cm}$ individually. The samples were

$22065 \%$ compressed by a $100 \mathrm{~mm}$ plate twice at a speed of $1 \mathrm{~mm} \mathrm{~s}^{-1}$ with $5 \mathrm{~s}$ between two

221 compresses. Hardness, springiness, cohesiveness, chewiness, and resilience were obtained

222 from the TPA profiles.

223

224

225

226

227

228

229

230

231

232

233

234

235

236

237

238

239

240

241

242

\subsection{Statistical analysis}

All measurements were repeated at least three times. Plots are shown as representative curves. Results are shown as the mean \pm standard deviation in bar charts and tables. The C-Cell parameters were analysed and compared using one-way analysis of variance (ANOVA) and Turkey's test at a significance level of $\mathrm{p}<0.05$ using IBM SPSS statistics version 26 (IBM Corp., Armonk, NY, USA).

\section{Results and discussion}

\subsection{Biochemical properties}

The moisture content, protein content, ash content, and lipid content of rice flour were $11.1 \%$, $7.23 \%, 0.42 \%$, and $2.8 \%$ respectively. That of PSY was $7.23 \%, 3.40 \%, 2.89 \%$, and $3.30 \%$ respectively (Ren, Yakubov, Linter, MacNaughtan \& Foster, Unpublished results-b). The amylose content of rice flour was $28.8 \%$.

\subsection{Dough rheological properties}

\subsubsection{Fundamental rheological analysis of dough properties}

The stress ramp data are shown in Figure 1. It can be seen (Figure 1a) that the shear strain increased with shear stress with different rates in different stress ranges. The replacement of rice flour by FC0 and FC60 significantly decreases the shear strain caused by a certain applied shear stress in the higher stress range $(>10 \mathrm{~Pa})$. The control dough $(\mathrm{F} 100)$ shows a relatively short transition from the linear-elastic deformation behaviour (shear strain increases linearly with shear stress) to flow behaviour and a yield point can be defined by calculating the 9 
243 deviation from the linearity at low shear stress range. However, when FC0 or FC60 is added,

244 it shows a long yield zone and yield point cannot be defined by this method. The longer yield 245 zone could due to the long cellulose fibres with various sizes. The viscosity from the same data 246 sets is plotted versus shear stress in Figure 1b. The viscosity plateau at low shear stress which 247 is similar to the Newtonian plateau is, however, possibly due to the fact that the doughs did not 248 reach a steady state. However, the start of viscosity decrease also indicates yield stress (Walls, 249 Caines, Sanchez \& Khan, 2003). Although it is still difficult to define the yield point due to a 250 long yield-flow transition, it can be seen that the replacement by FC0 and FC60 increased the stress at which doughs start to flow (significant decrease in viscosity). Similar enhancing effects on viscosity and yield stress by the addition of chestnut flour, which has high fibre content, in gluten free rice bread has been reported by Demirkesen et al. (2010) which can be assigned to the high entanglement and water binding ability of fibres.

255 The mechanical spectra of doughs are shown in Figure 2. In the mechanical spectra, it can be 256 seen that all doughs show solid like property with G' higher than G', The additions of FC0 or 257 FC60 increased both moduli and decreased tan $\delta$ suggesting a more solid like property, which 258 is in accordance with the strengthening effects of doughs evidenced by yield stress and 259 viscosity as discussed above.

260 The similarities in the general structure and rheological behaviours of different foods has been concluded and a weak gel model has been proposed by Gabriele et al. (2001). Foods can be described to be structured by strands constituted by weakly interacting flow units, and strongly interacting topological points, which is analogous to the classic 'true gel' with permanent crosslinked three dimensional network (Gabriele et al., 2001). The complex moduli $\left(\mathrm{G}^{*}\right)$ of gluten free doughs and angular frequencies $(\omega)$ were fitted with the weak gel model (equation (1)) with $\mathrm{R}^{2}$ higher than 0.95 and two model parameters, $\mathrm{A}$ and $\mathrm{z}$, were obtained and are listed in Table 4. It can be seen that A increased significantly with the addition of FC0 and FC60 which is in accordance with the increase of moduli. However, there is no significant difference in the value of $\mathrm{z}$ between all flour-replaced doughs, which suggests that there are no significant effects on the extension of the network of strands and rheological units. The increase in both moduli and parameter A and the decrease of $\tan \delta$ are more likely to be attributed to the increase in the strength of the topologically interactions and strand (rheological units) upon the additions of FC0 or FC60 fibres. In other words, it can be speculated that both flour particles and FC 
274 fibres are rigid fillers regardless of the difference in shapes. FC fibres are more rigid than the 275 hydrated flour particles and they compete for water with starch which further increases the 276 rigidity of the flour particles. Therefore, the doughs are strengthened by the addition of FC0 or 277 FC60.

278 The slopes of $\lg G^{\prime}$ versus $\lg \omega$ have a similar value of approximately 0.105 in all cases 279 regardless of the addition of FC0 or FC60, which is in accordance with the uninfluenced $\mathrm{z}$ 280 values. However, it is lower compared with most gluten free and wheat doughs which range 281 from 0.11 to 0.37 (Georgopoulos, Larsson \& Eliasson, 2004; Ronda et al., 2013; Tanner, Qi \& 282 Dai, 2008; Upadhyay, Ghosal \& Mehra, 2012; Villanueva, Harasym, Muñoz \& Ronda, 2019). 283 The low $\lg G^{\prime}$ versus $\lg \omega$ slope suggests approaching a true gel at the angular frequency range 284 studied. It was less influenced by FC0 and FC60 at the addition levels studied.

285 FC60 has more pronounced influence than FC0 even with very low addition levels (2 or 4\% 286 replacement). In fact, the effect of 2\% replacement by FC60 is similar to $10 \%$ replacement by 287 FC0 shown as similar shear strains and viscosities plotted versus shear stress, and similar 288 mechanical spectra and parameter A in the weak gel model. This could be explained by the 289 higher water holding ability of FC60 due to fibrillation treatment (Agarwal, Hewson \& Foster, 290 2018a; Ren, Linter \& Foster, 2020). Additionally, an increase in fibre entanglement can also 291 be expected as an outcome of fibrillation and FC60 appears as flocculates or aggregates (Ren 292 et al., 2020). It is likely that FC60 exists as highly entangled fibre aggregates which can be 293 considered as individual rheological units with enhanced properties. However, considering that 294 there was no significant difference in the value of the weak gel model parameter $\mathrm{z}$ between 295 FC0 and FC60 doughs, the interaction and entanglement between FC60 aggregates and FC60 296 aggregates and flour particles are limited therefore the influence on the extension of the 297 structural network of doughs are limited.

298 Table 4. Weak gel model parameters.

\begin{tabular}{|lcc|}
\hline & $\mathrm{A}\left(\mathrm{Pa} . \mathrm{s}^{1 / \mathrm{z}}\right)$ & $\mathrm{z}$ \\
\hline $\mathrm{F}(100)$ (control) & $3216 \pm 538^{\mathrm{a}}$ & $8.90 \pm 1.12^{\mathrm{a}}$ \\
$\mathrm{F}(98)+\mathrm{FC60}(2)$ & $10915 \pm 2055^{\mathrm{a}}$ & $9.06 \pm 1.04^{\mathrm{a}}$ \\
$\mathrm{F}(90)+\mathrm{FC} 0(10)$ & $11486 \pm 493^{\mathrm{a}}$ & $10.47 \pm 0.10^{\mathrm{a}}$ \\
$\mathrm{F}(90)+\mathrm{FC} 0(8)+\mathrm{FC} 60(2)$ & $21971 \pm 1733^{\mathrm{ab}}$ & $10.85 \pm 0.46^{\mathrm{a}}$ \\
$\mathrm{F}(80)+\mathrm{FC} 0(20)$ & $52447 \pm 4287^{\mathrm{bc}}$ & $9.34 \pm 0.35^{\mathrm{a}}$ \\
$\mathrm{F}(80)+\mathrm{FC} 0(18)+\mathrm{FC} 60(2)$ & $82416 \pm 11993^{\mathrm{c}}$ & $9.69 \pm 0.34^{\mathrm{a}}$ \\
$\mathrm{F}(80)+\mathrm{FC} 0(16)+\mathrm{FC} 60(4)$ & $80984 \pm 18218^{\mathrm{c}}$ & $9.08 \pm 0.27^{\mathrm{a}}$ \\
\hline
\end{tabular}


Data are shown as mean \pm standard deviation. Values with different letters in

the same column were significantly different $(\mathrm{p}<0.05)$.

299 The generalised Maxwell model was applied to estimate the dough rheological behaviours at a

300 longer time scale (slow deformation) (Figure 2). The arbitrarily decided $\lambda_{\mathrm{i}}$ and calculated

301 corresponding relaxation moduli $G_{i}$ are listed in Table 2. Ten pairs of $\lambda_{i}$ and $G_{i}$ along with a $G_{e}$

302 representing a single pure elastic component were used to calculate $G^{\prime}(\omega)$ and $G^{\prime \prime}(\omega)$ by

303 equation (3) and (4). The value of $\mathrm{G}_{\mathrm{e}}$ of each sample is either 0 or very low therefore it is not

304 listed in Table 2. A zero value of $\mathrm{G}_{\mathrm{e}}$ is typical for viscoelastic liquid of uncross-linked polymers

305 (Ferry, 1980). Therefore, gluten free bread doughs are structurally and rheologically analogous

306 to viscoelastic fluids instead of a solid.
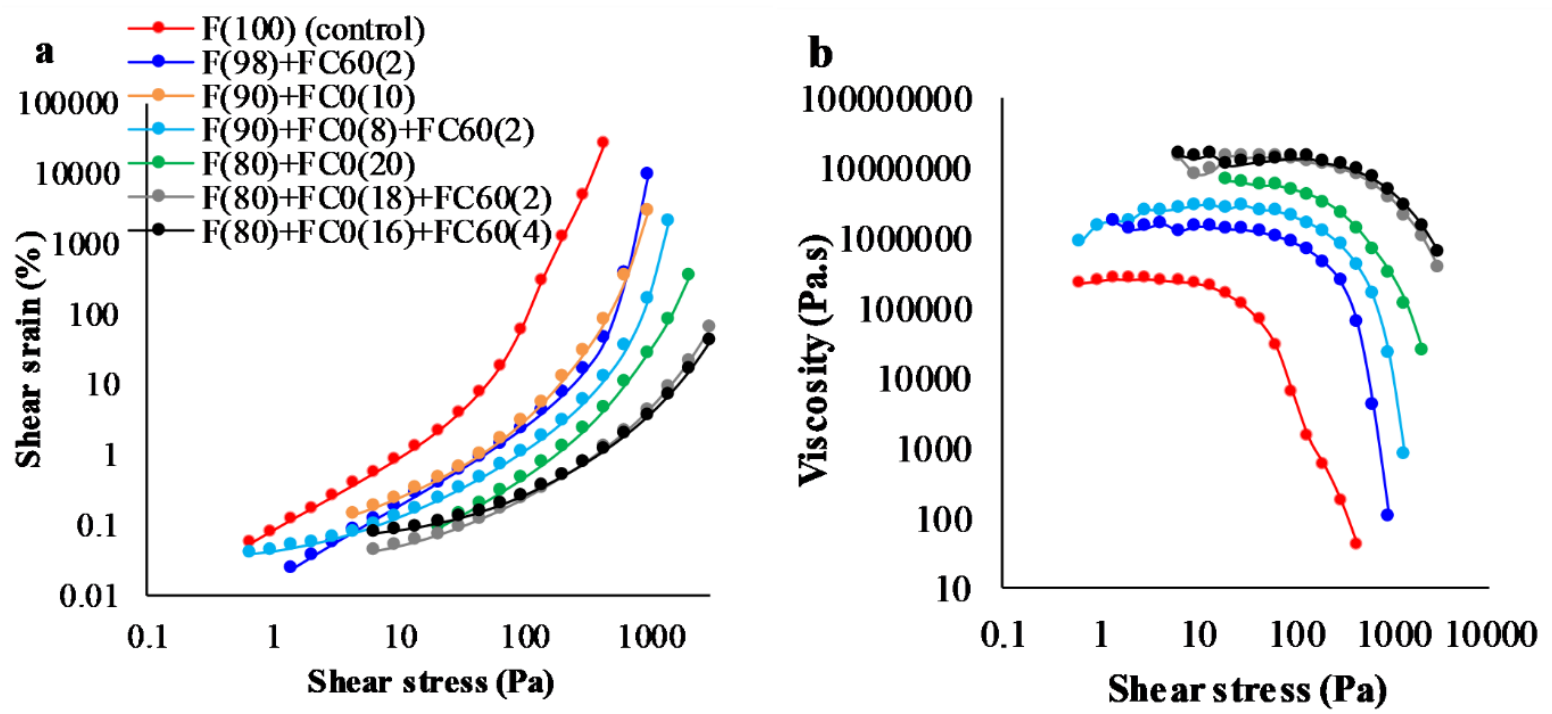

Figure 1. Shear stress ramp data (a) and viscosities plotted versus shear stress (b) of gluten free doughs. 


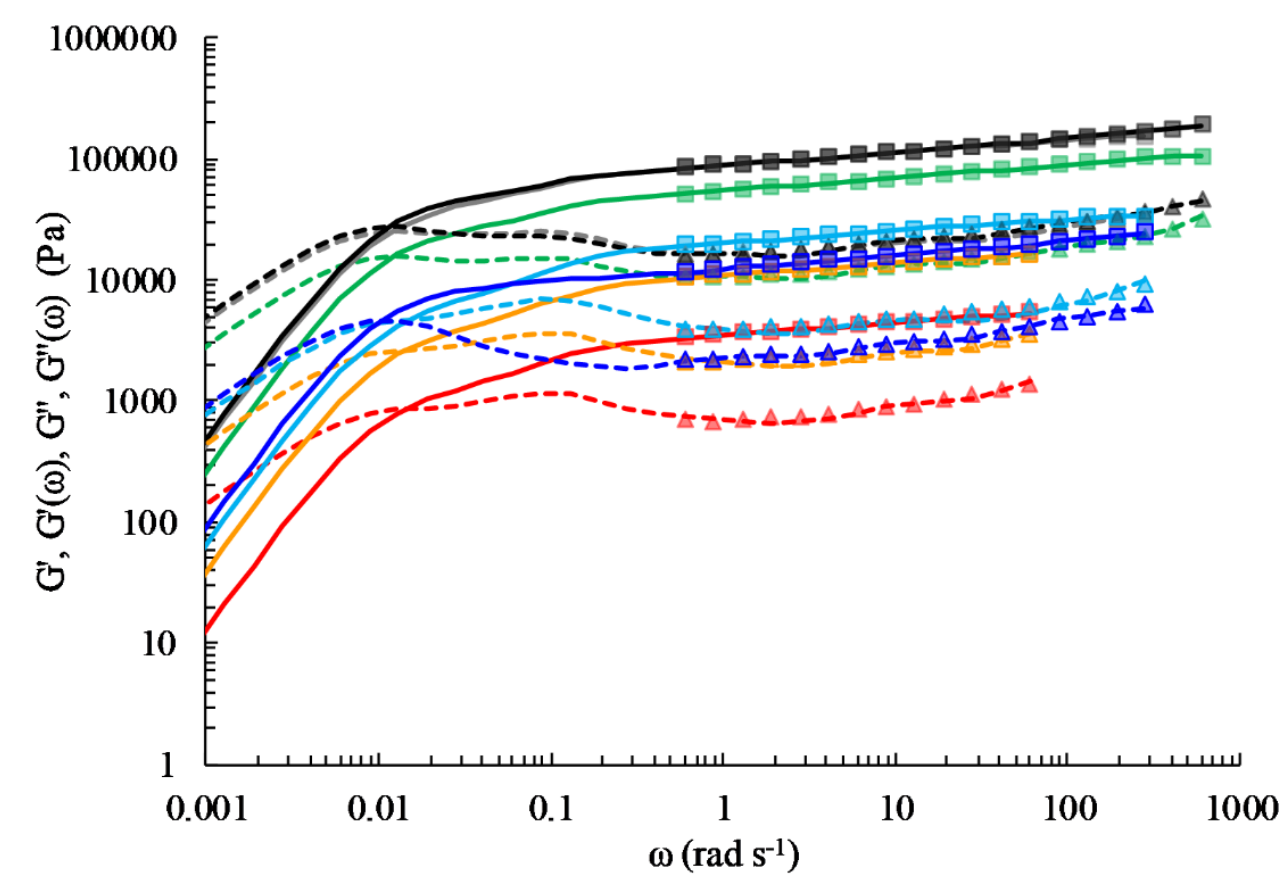

312 Figure 2. Mechanical spectra and curves calculated from generalised Maxwell model of $\mathrm{F}(100)$ (control)

313 (red), $\mathrm{F}(98)+\mathrm{FC60}(2)$ (dark blue), $\mathrm{F}(90)+\mathrm{FC0}(10)$ (yellow), $\mathrm{F}(90)+\mathrm{FC0}(8)+\mathrm{FC60}$ (2) (light blue),

$314 \mathrm{~F}(80)+\mathrm{FC0}(20)$ (green), $\mathrm{F}(80)+\mathrm{FC} 0(18)+\mathrm{FC} 60(2)$ (grey), and $\mathrm{F}(80)+\mathrm{FC0}(16)+\mathrm{FC} 60(4)$ (black).

315 Experimental storage moduli (G') and loss moduli (G') are shown by squire and triangle symbols

316 respectively and calculated $\mathrm{G}^{\prime}(\omega)$ and $\mathrm{G}^{\prime}$ ' $(\omega)$ are presented by solid lines and dashed lines respectively.

317 Plots are shown as representative curves from experiments run in triplicates.

318 The generalised Maxwell model expands the evaluable mechanical spectra to a lower

319 frequency range with $\mathrm{R}^{2}$ higher than 0.98 (Table 2). It can be seen in Figure 2 that all doughs

320 have a relaxation frequency of nearly $0.01 \mathrm{rad} \mathrm{s}^{-1}$. The influences of FC0 and FC60 additions

321 are insignificant which is in accordance with the uninfluenced $\mathrm{z}$ value in the weak gel model

322 that FC0 and FC60 do not significantly alter the extension of the rheological network. The

323 porous structure of loaves mainly forms, develops, and sometimes collapses during proofing

324 with low strain rates $\left(10^{-4}\right.$ to $10^{-3} \mathrm{~s}^{-1}$ as reported by Babin et al. (2006) and Grenier, Lucas and

325 Le Ray (2010)). The time scale is longer than the relaxation time (reciprocal of relaxation

326 frequency) of gluten free. In other words, doughs behave like fluids ( $\left.G^{\prime \prime}>G^{\prime}\right)$ in this low strain

327 rate range as found during proofing, which could be beneficial to the development of the loaf

328 structure. However, this also implies that only strengthening doughs might not be able to

329 provide efficient stability to maintain the porous structure. This could explain from, one aspect,

330 why air pockets and big voids in crumb structure is a common and difficult issue in the gluten

331 free bread production which have been widely reported (Haque \& Morris, 1994; McCarthy, 
332 Gallagher, Gormley, Schober \& Arendt, 2005; Nishita et al., 1976; Paciulli, Rinaldi, Cirlini, 333 Scazzina \& Chiavaro, 2016; Schober, Bean \& Boyle, 2007).

\subsubsection{Empirical rheological analysis of dough properties}

335 The influence of FC0 and FC60 addition on the behaviour of doughs under large deformation

336 were analysed by backward extrusion experiments. Dough stickiness was measured using an

337 SMS/Chen-Hoseney Dough Stickiness rig. As shown in Figure 3, the addition of FC0 and FC60

338 significantly increased dough firmness, cohesiveness, consistency, and index of viscosity,

339 which is in agreement with the increasing effects on yield stress and dynamic moduli. Similar

340 to what was observed in the fundamental rheological analysis, 2\% replacement by FC60 and

$34110 \%$ replacement by FC0 show similar values for these four parameters which indicate that

342 fibrillated cellulose is more efficient in strengthening doughs than untreated cellulose. The

343 additions of FC0 and FC60 generally decreased dough extensibility by approximately $20 \mathrm{~mm}$

344 while the effects of FC0 fibres tend to be quadratic as $20 \%$ replacement doughs have higher 345 extensibility than $10 \%$ replacement doughs by $6 \mathrm{~mm}$. Extensibility describes the flowability of

346 doughs in extensional flow. The negative effects of FC0 and FC60 are likely to be caused by

347 their strengthening effect which leads to higher resistance to flow. However, the slight increase

348 in extensibility by FC0 at higher addition level might because of its fibrous structure where the

349 fibres are much longer (intact) than FC60 (fibrillated).

350 The addition of both FC0 and FC60 increased dough strength and work of adhesion while 351 further increasing the addition levels decreased these two parameters. The stickiness was 352 decreased by the addition of both FC0 and FC60. The reduction of dough stickiness is in 353 agreement with the additions of fibres in wheat doughs (Collar, Santos \& Rosell, 2007; 354 Sangnark \& Noomhorm, 2004). Minimised stickiness is a desirable dough textual property in 355 the manufacture of wheat bread (Collar et al., 2007), where it is also beneficial to the handling 356 property. Generally, stickiness of a material is affected by both adhesive force and cohesive 357 (rheological) force which could oppose each other (Hoseney \& Smewing, 1999). The 358 SMS/Chen-Hoseney Dough Stickiness method minimises the interference from the bulk 359 rheology (Chen \& Hoseney, 1995). Therefore, it can be expected that the bulk rheology 360 property have less influence on dough stickiness measured in this experiment. Additionally, 361 the adhesive force is influenced by water surface tension (Hoseney \& Smewing, 1999). The 362 influence of water absorption on the stickiness of wheat doughs has also been highlighted 14 
363 (Armero \& Collar, 1997; Heddleson, Hamann, Lineback \& Slade, 1994). The influence on 364 dough stickiness is contrary to the influences on dough firmness and cohesiveness. In fact, they 365 show close negative correlations when fitted by power equations with $\mathrm{R}^{2}$ of 0.97 and 0.94 366 respectively. Therefore, the high water absorbability of FC0 and FC60 contribute both to the 367 strengthening of doughs, in addition to the contribution of the fibrous structure, and reduction 368 of stickiness. However, dough strength and work of adhesion reflect both the adhesive force 369 (stickness measured in this experiment) and cohesive force (bulk rheological, dough 370 strengthening effect). Therefore, they increased with the replacements by FC0 and FC60 at 371 lower addition levels but decreased coincidently with stickiness with further additions. A lower 372 stickiness and work of adhesion suggests better workability and handling properties of the 373 doughs. 

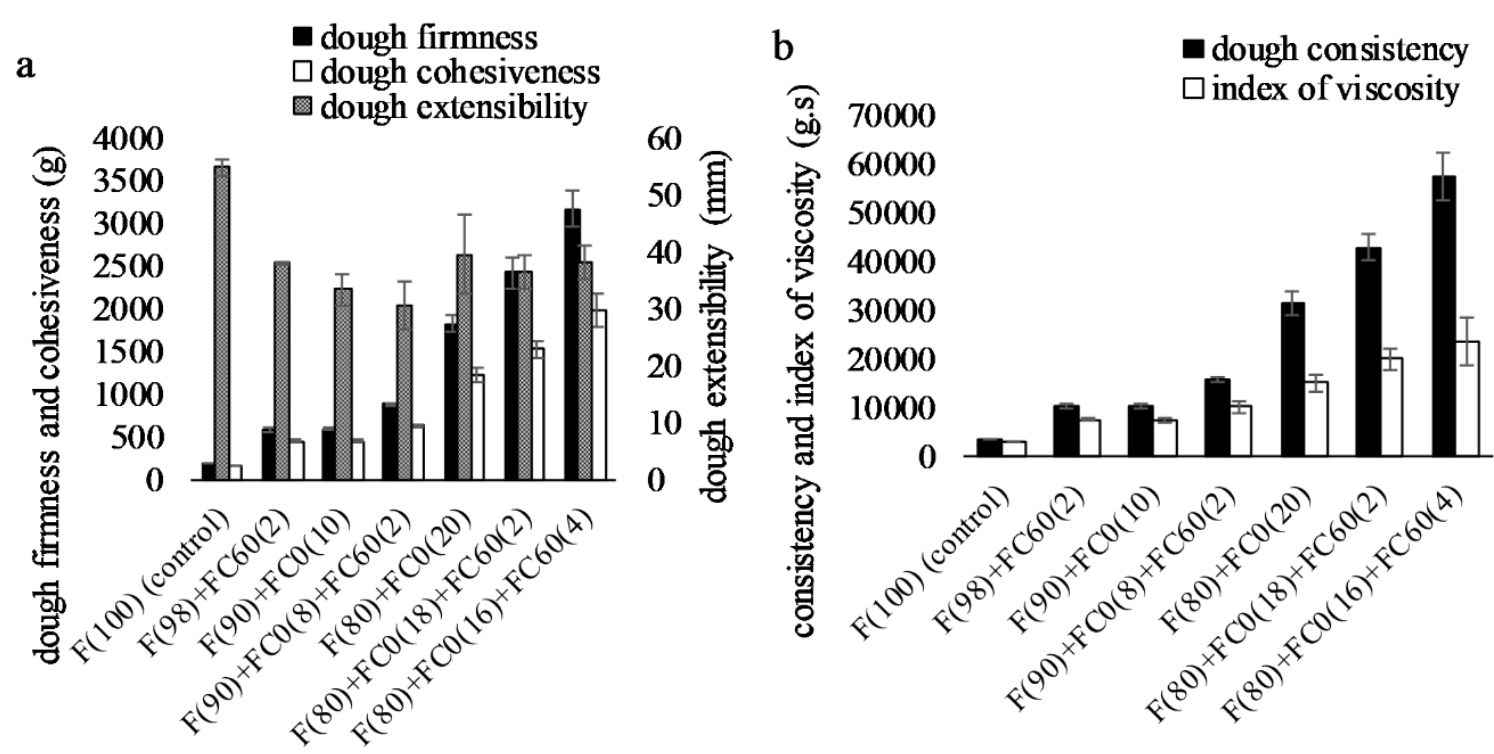

c

\section{$\square$ Work of Adhesion}

Dough Strength

- Stickiness

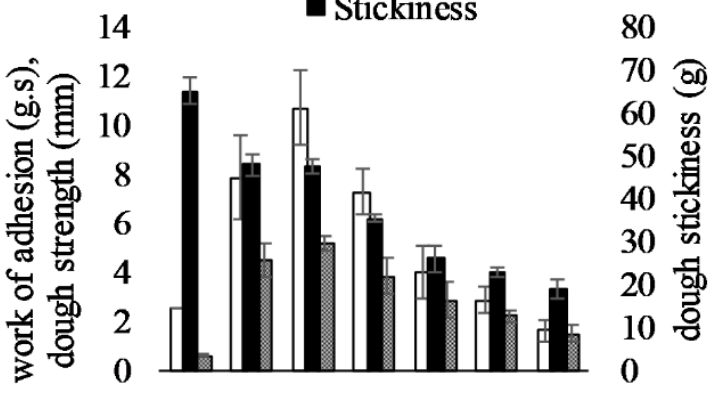

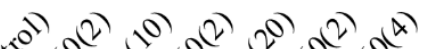

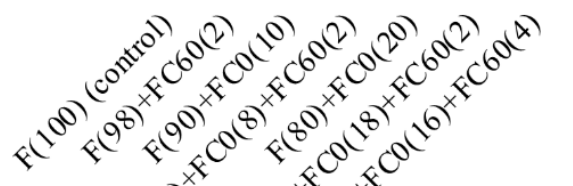

0

(2)

(10)

(60)

20 些

a dough consistency

स( से स० स०

Figure 3. Effects of cellulose and FC fibres additions on dough firmness, Cohesiveness, extensibility

376 (a), consistency, and index of viscosity (b) in backward extrusion measurements, and work of adhesion, dough strength, and dough stickiness (c) measured by SMS/Chen-Hoseney Dough Stickiness rig. Error bars represent the standard deviations averaging at least five replicates.

\subsection{Proofing behaviours}

380 The proofing behaviour of doughs are monitored by recording the volume increase of a piece

381 of dough sample in a measuring cylinder and the proofing profiles are shown in Figure 4 . The

382 differences in volume between gluten free doughs are less significant during the first 30

383 minutes. However, with increasing addition of FC0 or FC60, volume growth stopped earlier

384 during proofing which leads to lower final volume. Considering the correlations between low 
molecular weight sugars, yeast activity, and porosity kinetics (Romano, Toraldo, Cavella \& 386 Masi, 2007; Sahlström, Park \& Shelton, 2004), sucrose in the formula might promote the 387 volume increase during the early stage of proofing but be less influential after being consumed 388 by yeasts during the later stage. The reduction of flour, instead, limits the further fermentation 389 by yeast during the later stage of proofing. However, the difference between $\mathrm{F}(100)$ (control), $390 \mathrm{~F}(90)+\mathrm{FC} 0(10)$, and $\mathrm{F}(98)+\mathrm{FC} 60(2)$ are less pronounced although the flour was replaced by 391 only $2 \%$ and $10 \%$ respectively. Hence, the answer could also lie in rheological properties. As 392 shown by the generalised Maxwell model, doughs behave like fluids during proofing and 393 dough strengthening by FC0 and FC60 is less influential on the relaxation time. In addition, 394 according to the model derived by Shah, Campbell, McKee and Rielly (1998), dough rheology 395 is less influential during the early stage of proofing while it becomes critical during the later 396 stage (Mills, Wilde, Salt \& Skeggs, 2003). A rigid dough is highly resistant to deformation 397 which limits the expansion of gas cells during proofing (Lazaridou et al., 2007; Van Vliet, 398 Janssen, Bloksma \& Walstra, 1992). Therefore, the influences of FC0 and FC60 on proofing 399 behaviour during different stages can be also assigned to their strengthening effects on dough 400 rheology. There is no difference between maximum volume increase and final volume increase 401 indicating that doughs did not collapse during the proofing process even for $402 \mathrm{~F}(80)+\mathrm{FC} 0(16)+\mathrm{FC} 60(4)$, whose volume did not change after $40 \mathrm{~min}$ of proofing. This 403 stabilising effect is atributed to the dough strengthening by FC0 and FC60 additions as seen by 404 the rheological measurements. 


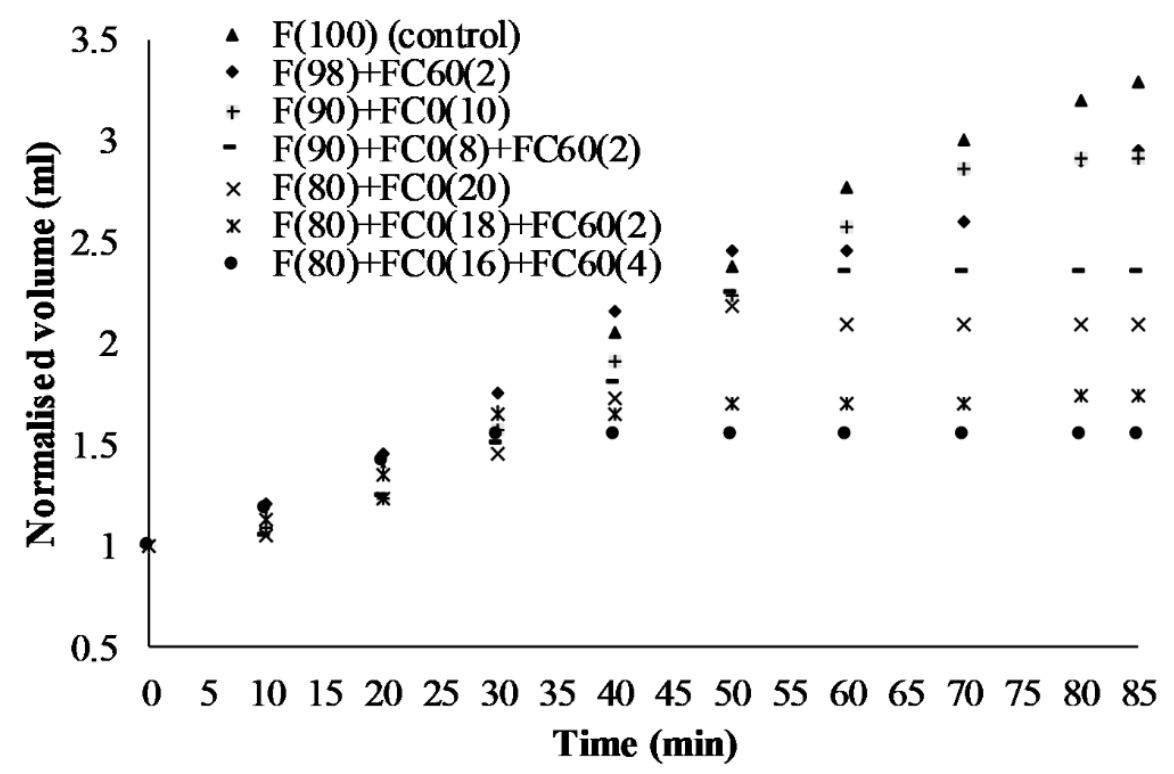

406 Figure 4. Proofing profiles (normalised) of gluten free doughs. Plots are shown as representative profiles 407 from experiments run in triplicates.

408 3.4. Rheological properties during heating and cooling

409 Pasting profiles describe viscosity changes of flour blends during heating and cooling which

410 typically describe the gelatinisation and retrogradation. The profiles are shown in Figure 5a. A

411 secondary peak at $85^{\circ} \mathrm{C}$ during cooling is observed at all curves due to the addition of psyllium,

412 and possible to a balance between interaction with amylose (James M. Cowley, personal

413 communication), formation of weak PSY gel particles, PSY particle interactions, and PSY

414 particle breakdown (Ren, Linter \& Foster, Unpublished results-a). The addition of FC0 and

415 FC60 both significantly decreased the pasting temperature (the onset of viscosity increase)

416 shown as a small shoulder before the main viscosity peak. The reduction of pasting temperature

417 is widely observed for most starch/hydrocolloid mixtures (BeMiller, 2011;

418 Naruenartwongsakul, Chinnan, Bhumiratana \& Yoovidhya, 2004; Sullo \& Foster, 2010). It is

419 also observed for starch and bacterial cellulose mixtures (Díaz-Calderón et al., 2018). In the

420 mixture of MC and starch, the thermal gelation of MC, which occurs at a lower temperature

421 than the significant swelling of starch granules, leads to an increase in starch concentration and,

422 therefore, enhanced starch granule interactions and increase in viscosity (Sullo \& Foster, 2010).

423 Naruenartwongsakul et al. (2004) suggested that the concentration increase of starch is due to

424 water competition with MC. Therefore, water and volume competition might also explain the 425 reduction of pasting temperature of FC0(FC60)/flour mixtures. When $20 \%$ of flour was 
426 replaced by FC0, the further addition of FC60 lead to another smaller shoulder at a lower 427 temperature, which suggests that FC60 is more powerful than FC0 in the competition with 428 starch for volume and water due to its higher abilities to hold water and to occupy volume 429 (Agarwal et al., 2018a; Ren et al., 2020).

430 Replacement by FC0 decreased the overall viscosity, peak time and setback while it increased 431 breakdown. The decrease of overall viscosity, including peak, and setback is, due to the 432 decrease in starch concentration, as it is replaced by FC0 which does not swell as starch 433 granules nor retrograde as amylose. The reduction of swellable starch granules leads to a 434 reduction of the ability to be closely packed which appears as early onset of breakdown. The 435 increased breakdown is likely to be due to the enhancement of shear force exerted on starch 436 granules by the fibrous structure of FC0. However, the substitution by FC60 result in an 437 increase in the overall viscosity and decrease in breakdown. Fibrillated cellulose (FC60) 438 appears as flocculates or aggregates (Agarwal et al., 2018b; Ren et al., 2020) which can be 439 considered similar to swollen starch granules or granule fragments with freed fibrils similar to 440 leaked amylose. The increase of viscosity indicates that FC60 is similar to or even more 441 efficient than starch in increasing viscosity while it does not breakdown as starch granules. 442 Therefore, the functionality of fibrillated cellulose has an effective enhancement of overall 443 composite properties beyond the effects of the 'inert' unfibrillated filler. 

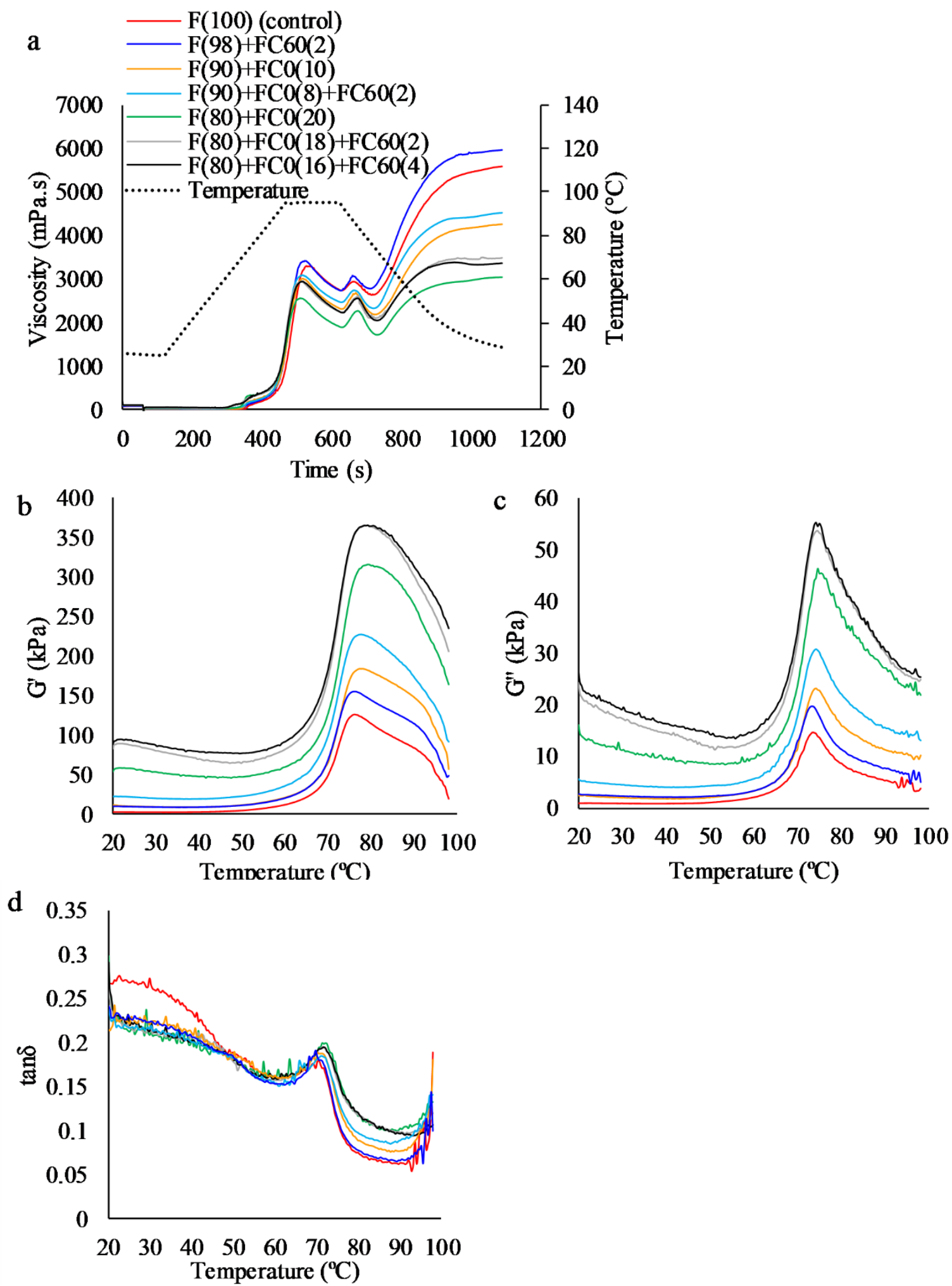

445 Figure 5. Pasting profiles (a), storage moduli G' (b), loss moduli G' (c), and loss factor tan $\delta$ of flours 446 blends. G' and G' were recorded with a heating rate of $2.6^{\circ} \mathrm{C} \mathrm{min}^{-1}$. 
447 The rheological property of doughs during cooking was monitored by temperature sweep tests 448 (Figure $5 \mathrm{~b}, \mathrm{c}$, and $\mathrm{d}$ ) with a temperature profile mimicking the temperature changes during 449 baking. It can be seen that G' and G', decreased slightly with the temperature increasing up to 450 approximately $50{ }^{\circ} \mathrm{C}$, especially with $20 \%$ replacement of flour by FC0 and FC60, which could 451 be attributed to the softening induced by the increase of temperature. The initial G' and G', 452 decrease was accompanied by a moderate decrease in tan $\delta$ until approximately $60{ }^{\circ} \mathrm{C}$, which 453 can be attributed to slow swelling of starch granules which was not influenced by the 454 replacement by FC0 and FC60. It can be speculated that the slow granule swelling overcomes the softening effect due to heating, therefore the temperature-induced softening ( $G^{\prime}$ and $G$ ', decrease) became more pronounced when flour was replaced by FC0 and FC60. With further increase in temperature, $G^{\prime}$ and G', significantly increased to a peak because of a dramatic swelling and volume filling of starch granules which are eventually close-packed at the peaks in moduli. In contrast to pasting temperature, the onsets of $G^{\prime}$ and $G$ ', increase shifted to a 460 higher temperature when FC0 and/or FC60 were added. FC0/FC60 and flour were already 461 closely packed with the higher concentration in doughs compared to the experimental condition of RVA. When the starch content was reduced, the starch granules needed to swell to a larger volume at a higher temperature to overcome the initial temperature-controlled softening (moduli decrease) and to contribute to the overall rigidity ( $\mathrm{G}^{\prime}$ increase). It was also different from pasting properties that both the addition of FC0 or FC60 increased the peaks of $\mathrm{G}^{\prime}$ and G'. This could also be due to the closely packed structure where the swelling and rigidity changes of starch granules can be detected and, as demonstrated by the rheological properties in both fundamental and empirical experiments, the fibrous structure and high water binding ability of FC0 and FC60. FC0 and FC60 competed for water with starch, which restrained the swelling of the granules, increased their rigidity, and, hence, further increased moduli. As for $\tan \delta$, it showed a peak at about $70{ }^{\circ} \mathrm{C}$. Baldino et al. (2018) also observed the peaks of phase angle at $60.9{ }^{\circ} \mathrm{C}$ when gluten free doughs contained HPMC which is related to the phase separation of HPMC. However, comparing to their observation, $\tan \delta$ peaks in Figure $5 \mathrm{~d}$ had lower value and occurred at a higher temperature but $\mathrm{MC}$ has a lower gelation temperature than HPMC. Moreover, phase separation between amylose and amylopectin in baked wheat bread crumb has been reported (Hug-Iten, Handschin, Conde-Petit \& Escher, 1999). Therefore, the $\tan \delta$ peaks are possibly attributed to the phase separation between amylose and amylopectin. The reasons for G' and G', decreasing after peaks might be the melting of remaining crystallites, 
separation of amylose and amylopectin, amylopectin matrix breakdown, and disentanglement

480 of amylopectin chains, which lead to granule softening (Keetels, vanVliet \& Walstra, 1996).

\subsection{Bread qualities}

482 The influence of the addition of FC0 and/or FC60 on specific volumes and baking loss of starch

483 reduced gluten free bread are shown in Figure 6a. The influence on the moisture content of the

484 centre crumb is insignificant which is not shown. The baking loss is significantly reduced upon

485 the additions of FC0 and/or, especially, FC60, which could be attributed to their high water

486 holding ability. It could also because of the denser crumb structure where water evaporation

487 within the gas cells was restrained but water diffusion in the crumb matrix became more

488 dominant. The FC0/FC60 additions significantly reduced the specific volume, which is the

489 same as their influences on final proofing volume. The close correlation between loaf volume

490 and final proofing volume is also documented in a previous study (Ren et al., Unpublished

491 results-a), which suggests that loaves are stable during both the later stage of proofing and oven

492 rising. The detrimental effect on specific volume of fibre addition and generation of denser

493 crumb structure have also been observed in studies on both wheat bread and gluten free bread

494 (Demirkesen et al., 2010; Gómez, Oliete, Caballero, Ronda \& Blanco, 2008; Gomez, Ronda,

495 Blanco, Caballero \& Apesteguia, 2003).

496 The crumb was evaluated by C Cell and images are shown in Figure 7. Six C Cell parameters

497 are chosen to describe the crumb structures (Table 5). The area of cells indicates the percentage

498 of the cells of the total slice area and the number of cells is the number of discrete gas cells.

499 The addition of FC0 and/or FC60 increased the number of cells but decreased the area of cells

500 and wall thickness, and, consequently, reduced cell diameters. With the fact that the specific

501 volume was decreased, which led to a smaller slice area, a finer crumb structure was obtained.

502 Comparing to the addition of FC0, FC60 was more effective in altering these parameters. It

503 can be attributed to the fibrous structure of FC0 and, especially, FC60, which formed a fine

504 fibrous framework. The fibrous framework stabilised the porous structure of doughs and loaves 505 and allowed the gelatinised starch to attach on and, therefore, reinforce the starch matrix.

506 Additionally, area of holes and top concavity, which reflect the structural instability are not

507 significant among all loaves. 
508 The texture properties of bread were evaluated by TPA. Hardness, springiness, and 509 cohesiveness are shown in Figure 6b. Specific volume is negatively correlated with hardiness 510 due to a denser crumb structure. As expected, loaves with FC0 and FC60, which have lower 511 specific volume, have a harder crumb. They also show lower springiness and cohesiveness,

512 which indicates that the crumb is less resistant to the applied large deformation. Good wheat 513 bread is expected to have a thinner cell wall and uniform cells which, therefore, has softer and 514 more elastic texture providing good mouth feel (Scanlon \& Zghal, 2001). However, due to the 515 absence of gluten and the more compact crumb structure, the starch reduced gluten free loaves 516 show the opposite that they have smaller cells, thinner cell walls, but harder and less springy 517 crumb.

a

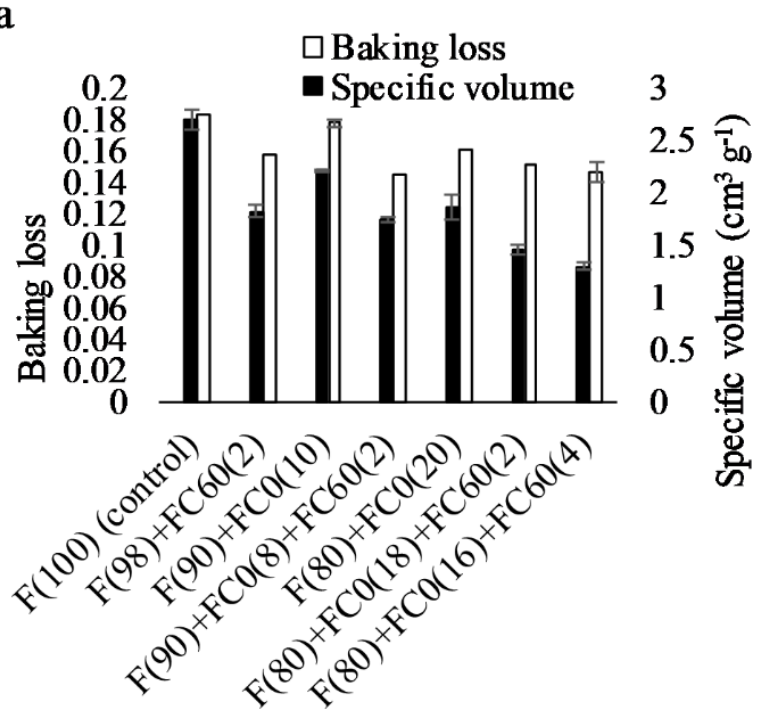

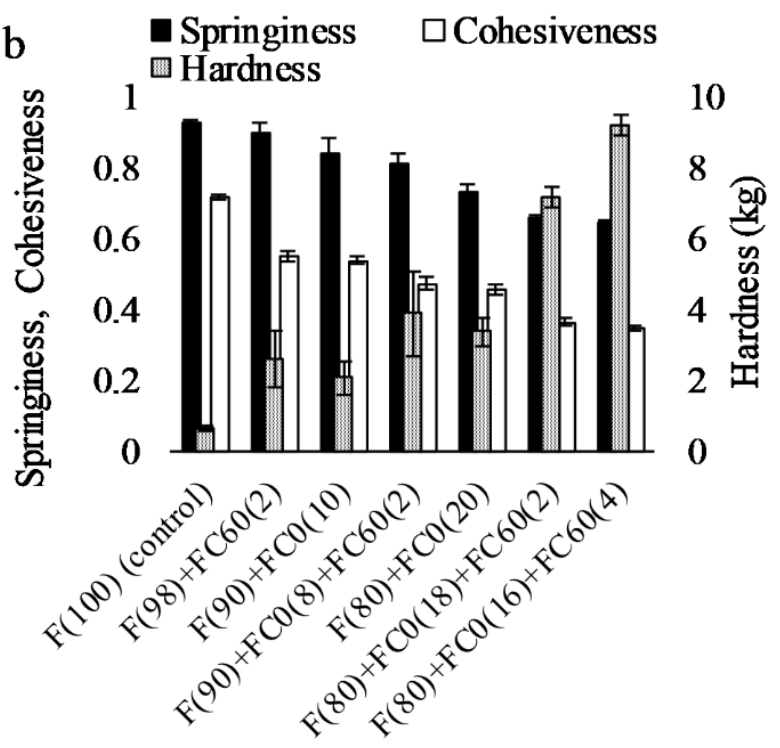

Figure 6. Baking lose, specific volume (a), and textural properties (b) of starch replaced gluten free breads. Error bars represent the standard deviations averaging four replicates. 

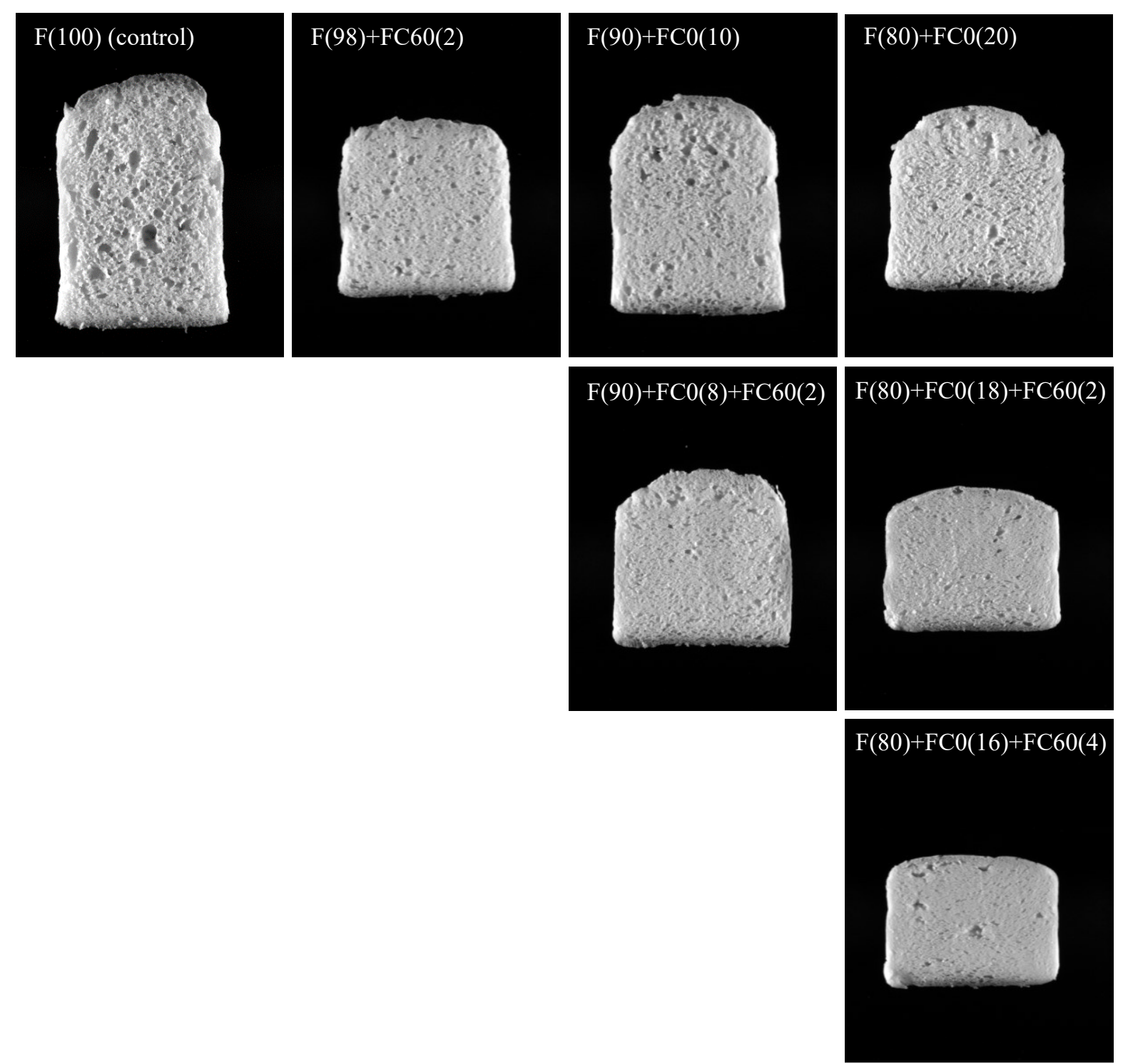

Figure 7. Images of starch replaced gluten free breads.

Table 5. C-Cell parameters of starch redplaced gluten free bread.

\begin{tabular}{|lllllll|}
\hline & $\begin{array}{l}\text { Top } \\
\text { Concavity } \\
(\%)\end{array}$ & Number of Cells & $\begin{array}{l}\text { Area of } \\
\text { Cells (\%) }\end{array}$ & $\begin{array}{l}\text { Area of } \\
\text { Holes (\%) }\end{array}$ & $\begin{array}{l}\text { Wall } \\
\text { Thickness } \\
(\mathrm{mm})\end{array}$ & $\begin{array}{l}\text { Cell } \\
\text { Diameter } \\
(\mathrm{mm})\end{array}$ \\
\hline $\mathrm{F}(100)$ (control) & $0.070 .02^{\mathrm{a}}$ & $3523.25 \pm 27.90^{\mathrm{a}}$ & $50.83 \pm 0.96^{\mathrm{a}}$ & $2.41 \pm 0.39^{\mathrm{ac}}$ & $0.50 \pm 0.01^{\mathrm{a}}$ & $2.61 \pm 0.07^{\mathrm{a}}$ \\
$\mathrm{F}(98)+\mathrm{FC} 60(2)$ & $0.78 \pm 0.38^{\mathrm{b}}$ & $3986.75 \pm 91.51^{\mathrm{ab}}$ & $44.73 \pm 0.84^{\mathrm{b}}$ & $1.33 \pm 0.88^{\mathrm{abc}}$ & $0.44 \pm 0.01^{\mathrm{cd}}$ & $1.53 \pm 0.07^{\mathrm{b}}$ \\
$\mathrm{F}(90)+\mathrm{FC} 0(10)$ & $0.45 \pm 0.14^{\mathrm{bc}}$ & $3781.50 \pm 84.82^{\mathrm{ab}}$ & $48.20 \pm 0.57^{\mathrm{c}}$ & $1.43 \pm 0.81^{\mathrm{abc}}$ & $0.46 \pm 0.01^{\mathrm{b}}$ & $1.88 \pm 0.09^{\mathrm{c}}$ \\
$\mathrm{F}(90)+\mathrm{FC} 0(8)+\mathrm{FC} 60(2)$ & $0.56 \pm 0.07^{\mathrm{bc}}$ & $4033.50 \pm 69.00^{\mathrm{b}}$ & $45.00 \pm 0.43^{\mathrm{b}}$ & $0.85 \pm 0.48^{\mathrm{ab}}$ & $0.43 \pm 0.00^{\mathrm{d}}$ & $1.44 \pm 0.02^{\mathrm{b}}$ \\
$\mathrm{F}(80)+\mathrm{FC} 0(20)$ & $0.47 \pm 0.07^{\mathrm{bc}}$ & $3559.75 \pm 246.75^{\mathrm{a}}$ & $47.08 \pm 0.49^{\mathrm{c}}$ & $0.26 \pm 0.28^{\mathrm{b}}$ & $0.46 \pm 0.01^{\mathrm{bc}}$ & $1.76 \pm 0.13^{\mathrm{c}}$ \\
$\mathrm{F}(80)+\mathrm{FC}(18)+\mathrm{FC} 60(2)$ & $0.27 \pm 0.04^{\mathrm{ac}}$ & $4084.50 \pm 362.24^{\mathrm{b}}$ & $43.88 \pm 0.96^{\mathrm{bd}}$ & $1.29 \pm 0.82^{\mathrm{abc}}$ & $0.39 \pm 0.01^{\mathrm{e}}$ & $1.14 \pm 0.10^{\mathrm{d}}$ \\
$\mathrm{F}(80)+\mathrm{FC}(16)+\mathrm{FC} 6(4)$ & $0.21 \pm 0.04^{\mathrm{ac}}$ & $4065.00 \pm 274.07^{\mathrm{b}}$ & $42.73 \pm 0.78^{\mathrm{d}}$ & $2.56 \pm 0.94^{\mathrm{c}}$ & $0.38 \pm 0.01^{\mathrm{e}}$ & $1.09 \pm 0.06^{\mathrm{d}}$ \\
\hline
\end{tabular}

Dara are shown as mean \pm standard deviation. Values with different letters in the same column were significantly different $(\mathrm{p}<0.05)$. 


\section{Conclusion}

526 The conducted study aimed to evaluate the starch reduction of gluten free doughs and bread by 527 FC0 and FC60 fibres. The fundamental dough rheological properties were analysed using the 528 weak gel model and the generalised Maxwell model. The addition of FC0 and/or FC60 529 significantly increased the dough strength shown as increased viscosity, yield zone, and storage 530 and loss moduli measured by fundamental rheological measurements, and dough firmness, 531 cohesiveness, consistency and index of viscosity measured by empirical measurements. As the outcome of the fibrillation treatment, with high water absorbability and entangled fibrous aggregate structure, FC60 is more efficient than FC0 in altering the rheological properties.

534 Further analysis of the mechanical spectra by generalised Maxwell model suggests that gluten

535 free doughs are structurally and rheologically analogous to a viscoelastic fluid instead of a solid.

536 It also suggests that doughs are flowable at the time scales of structure developing during 537 proofing which is longer than their relaxation times. Generally, a comprehensive design of 538 experiments including both fundamental and empirical analysis would be necessary to maximise the characterisation of doughs. Rheological properties of doughs influence the proofing behaviour where the addition of FC0/FC60 mainly restrained the volume increase during the later stage of proofing (after approximately $30 \mathrm{~min}$ ). The fibrillated cellulose has an effective enhancement of overall composite properties beyond the effects of the 'inert' unfibrillated filler. Fibrillation of cellulose increased its similarity of pasting properties to flour in a cellulose/flour blend. Volume and water competition of FC0 and FC60 restricted the hydration and swelling of starch granules significantly influencing the pasting and thermalmechanical behaviours of the blends. The additions of FC0 and FC60 decrease the specific volume of gluten free loaves, which is correlated with the decrease of final volume during proofing. The additions of FC0 and FC60 generate denser and harder but finer crumb. FC0 and, especially, FC60, play a role as a framework which stabilise the porous dough/crumb structure and reinforce the starch matrix. The further improvement of cellulose enriched gluten free bread might rely on the structuring of added hydrocolloids and fibrillated cellulose and optimisation of formulation including water addition levels to increase specific volume by obtaining desired rheological properties of doughs. 


\section{Acknowledgement}

555 This work was supported by the University of Nottingham (Vice-Chancellor's Scholarship for

556 Research Excellence (International)) and PepsiCo. The views and opinions expressed in this

557 manuscript are those of the author and do not necessarily reflect the position or policy of 558 PepsiCo. 


\section{Reference}

Agarwal, D., Hewson, L. \& Foster, T. J. (2018a). A comparison of the sensory and rheological properties of different cellulosic fibres for food. Food \& Function, 9(2), 1144-1151.

Agarwal, D., MacNaughtan, W. \& Foster, T. J. (2018b). Interactions between microfibrillar cellulose and carboxymethyl cellulose in an aqueous suspension. Carbohydrate Polymers, 185, 112-119.

Armero, E. \& Collar, C. (1997). Texture properties of formulated wheat doughs Relationships with dough and bread technological quality. Zeitschrift für Lebensmitteluntersuchung und Forschung A, 204(2), 136-145.

Aziz, I., Lewis, N. R., Hadjivassiliou, M., Winfield, S. N., Rugg, N., Kelsall, A., Newrick, L. \& Sanders, D. S. (2014). A UK study assessing the population prevalence of self-reported gluten sensitivity and referral characteristics to secondary care. European Journal of Gastroenterology \& Hepatology, 26(1), 33-39.

Babin, P., Della Valle, G., Chiron, H., Cloetens, P., Hoszowska, J., Pernot, P., Réguerre, A. L., Salvo, L. \& Dendievel, R. (2006). Fast X-ray tomography analysis of bubble growth and foam setting during breadmaking. Journal of Cereal Science, 43(3), 393-397.

Baldino, N., Laitano, F., Lupi, F. R., Curcio, S. \& Gabriele, D. (2018). Effect of HPMC and CMC on rheological behavior at different temperatures of gluten-free bread formulations based on rice and buckwheat flours. European Food Research and Technology, 244(10), 1829-1842.

Baumgaertel, M. \& Winter, H. H. (1992). Interrelation between continuous and discrete relaxation time spectra. Journal of Non-Newtonian Fluid Mechanics, 44, 15-36.

BeMiller, J. N. (2011). Pasting, paste, and gel properties of starch-hydrocolloid combinations. Carbohydrate Polymers, 86(2), 386-423.

Bousquières, J., Michon, C. \& Bonazzi, C. (2017). Functional properties of cellulose derivatives to tailor a model sponge cake using rheology and cellular structure analysis. Food Hydrocolloids, 70, 304-312.

Capristo, E., Addolorato, G., Mingrone, G., De Gaetano, A., Greco, A. V., Tataranni, P. A. \& Gasbarrini, G. (2000). Changes in body composition, substrate oxidation, and resting metabolic rate in adult celiac disease patients after a 1-y gluten-free diet treatment. The American Journal of Clinical Nutrition, 72(1), 76-81.

Catassi, C., Anderson, R. P., Hill, I. D., Koletzko, S., Lionetti, E., Mouane, N., Schumann, M. \& Yachha, S. K. (2012). World perspective on celiac disease. Journal of Pediatric Gastroenterology and Nutrition, 55(5), 494-499.

Chen, W. Z. \& Hoseney, R. C. (1995). Development of an objective method for dough stickiness. $L W T$ - Food Science and Technology, 28(5), 467-473. 
Collar, C., Santos, E. \& Rosell, C. M. (2007). Assessment of the rheological profile of fibre-enriched bread doughs by response surface methodology. Journal of Food Engineering, 78(3), 820-826.

Czaja-Bulsa, G. (2015). Non coeliac gluten sensitivity - A new disease with gluten intolerance. Clinical Nutrition, 34(2), 189-194.

Demirkesen, I., Mert, B., Sumnu, G. \& Sahin, S. (2010). Utilization of chestnut flour in gluten-free bread formulations. Journal of Food Engineering, 101(3), 329-336.

Di Sabatino, A. \& Corazza, G. R. (2009). Coeliac disease. The Lancet, 373(9673), 1480-1493.

Díaz-Calderón, P., MacNaughtan, B., Hill, S., Foster, T., Enrione, J. \& Mitchell, J. (2018). Changes in gelatinisation and pasting properties of various starches (wheat, maize and waxy maize) by the addition of bacterial cellulose fibrils. Food Hydrocolloids, 80, 274-280.

Djordjevic, M., Soronja-Simovic, D., Nikolic, I., Djordjevic, M., Seres, Z. \& Milasinovic-Seremesic, M. (2019). Sugar beet and apple fibres coupled with hydroxypropylmethylcellulose as functional ingredients in gluten-free formulations: Rheological, technological and sensory aspects. Food Chemistry, 295, 189-197.

Fasano, A. \& Catassi, C. (2001). Current approaches to diagnosis and treatment of celiac disease: An evolving spectrum. Gastroenterology, 120(3), 636-651.

Ferry, J. D. (1980). Viscoelastic properties of polymers (3rd ed.). New York: John Wiley \& Sons.

Gabriele, D., de Cindio, B. \& D'Antona, P. (2001). A weak gel model for foods. Rheologica Acta, 40(2), 120-127.

Georgopoulos, T., Larsson, H. \& Eliasson, A.-C. (2004). A comparison of the rheological properties of wheat flour dough and its gluten prepared by ultracentrifugation. Food Hydrocolloids, 18(1), 143-151.

Gómez, M., Oliete, B., Caballero, P. A., Ronda, F. \& Blanco, C. A. (2008). Effect of nut paste enrichment on wheat dough rheology and bread volume. Food Science and Technology International, 14(1), 57-65.

Gomez, M., Ronda, F., Blanco, C. A., Caballero, P. A. \& Apesteguia, A. (2003). Effect of dietary fibre on dough rheology and bread quality. European Food Research and Technology, 216(1), 5156.

Grenier, D., Lucas, T. \& Le Ray, D. (2010). Measurement of local pressure during proving of bread dough sticks: Contribution of surface tension and dough viscosity to gas pressure in bubbles. Journal of Cereal Science, 52(3), 373-377.

Hager, A.-S., Wolter, A., Czerny, M., Bez, J., Zannini, E., Arendt, E. K. \& Czerny, M. (2012). Investigation of product quality, sensory profile and ultrastructure of breads made from a range of commercial gluten-free flours compared to their wheat counterparts. European Food Research and Technology, 235(2), 333-344. 
Haque, A. \& Morris, E. R. (1994). Combined use of ispaghula and HPMC to replace or augment gluten in breadmaking. Food Research International, 27(4), 379-393.

Heddleson, S. S., Hamann, D. D., Lineback, D. R. \& Slade, L. (1994). Pressure-sensitive adhesive properties of wheat-flour dough and the influence of temperature, separation rate, and moisture-content. Cereal Chemistry, 71(6), 564-570.

Herrick, F. W., Casebier, R. L., Hamilton, J. K. \& Sandberg, K. R. (1983). Microfibrillated cellulose: morphology and accessibility. In Journal of Applied Polymer Science: Applied Polymer Symposium;(United States) (Vol. 37): ITT Rayonier Inc., Shelton, WA.

Hoseney, R. C. \& Smewing, J. (1999). Instrumental measurement of stickiness of doughs and other foods. Journal of Texture Studies, 30(2), 123-136.

Hug-Iten, S., Handschin, S., Conde-Petit, B. \& Escher, F. (1999). Changes in starch microstructure on baking and staling of wheat bread. Food Science and Technology-Lebensmittel-Wissenschaft \& Technologie, 32(5), 255-260.

Kaufman, R. C., Wilson, J. D., Bean, S. R., Herald, T. J. \& Shi, Y. C. (2015). Development of a 96well plate iodine binding assay for amylose content determination. Carbohydrate Polymers, $115,444-447$.

Keetels, C. J. A. M., vanVliet, T. \& Walstra, P. (1996). Gelation and retrogradation of concentrated starch systems .1. Gelation. Food Hydrocolloids, 10(3), 343-353.

Laun, H. M. (1986). Prediction of elastic strains of polymer melts in shear and elongation. Journal of Rheology, 30(3), 459-501.

Lazaridou, A., Duta, D., Papageorgiou, M., Belc, N. \& Biliaderis, C. G. (2007). Effects of hydrocolloids on dough rheology and bread quality parameters in gluten-free formulations. Journal of Food Engineering, 79(3), 1033-1047.

López-Rubio, A., Lagaron, J. M., Ankerfors, M., Lindström, T., Nordqvist, D., Mattozzi, A. \& Hedenqvist, M. S. (2007). Enhanced film forming and film properties of amylopectin using micro-fibrillated cellulose. Carbohydrate Polymers, 68(4), 718-727.

McCarthy, D. F., Gallagher, E., Gormley, T. R., Schober, T. J. \& Arendt, E. K. (2005). Application of response surface methodology in the development of gluten-free bread. Cereal Chemistry, 82(5), 609-615.

Mills, E. N. C., Wilde, P. J., Salt, L. J. \& Skeggs, P. (2003). Bubble formation and stabilization in bread dough. Food and Bioproducts Processing, 81(3), 189-193.

Nakagaito, A. N. \& Yano, H. (2004). The effect of morphological changes from pulp fiber towards nano-scale fibrillated cellulose on the mechanical properties of high-strength plant fiber based composites. Applied Physics a-Materials Science \& Processing, 78(4), 547-552. 
Naruenartwongsakul, S., Chinnan, M. S., Bhumiratana, S. \& Yoovidhya, T. (2004). Pasting characteristics of wheat flour-based batters containing cellulose ethers. LWT-Food Science and Technology, 37(4), 489-495.

Ng, M., Fleming, T., Robinson, M., Thomson, B., Graetz, N., Margono, C., Mullany, E. C., Biryukov, S., Abbafati, C., Abera, S. F., Abraham, J. P., Abu-Rmeileh, N. M. E., Achoki, T., AlBuhairan, F. S., Alemu, Z. A., Alfonso, R., Ali, M. K., Ali, R., Guzman, N. A., Ammar, W., Anwari, P., Banerjee, A., Barquera, S., Basu, S., Bennett, D. A., Bhutta, Z., Blore, J., Cabral, N., Nonato, I. C., Chang, J.-C., Chowdhury, R., Courville, K. J., Criqui, M. H., Cundiff, D. K., Dabhadkar, K. C., Dandona, L., Davis, A., Dayama, A., Dharmaratne, S. D., Ding, E. L., Durrani, A. M., Esteghamati, A., Farzadfar, F., Fay, D. F. J., Feigin, V. L., Flaxman, A., Forouzanfar, M. H., Goto, A., Green, M. A., Gupta, R., Hafezi-Nejad, N., Hankey, G. J., Harewood, H. C., Havmoeller, R., Hay, S., Hernandez, L., Husseini, A., Idrisov, B. T., Ikeda, N., Islami, F., Jahangir, E., Jassal, S. K., Jee, S. H., Jeffreys, M., Jonas, J. B., Kabagambe, E. K., Khalifa, S. E. A. H., Kengne, A. P., Khader, Y. S., Khang, Y.-H., Kim, D., Kimokoti, R. W., Kinge, J. M., Kokubo, Y., Kosen, S., Kwan, G., Lai, T., Leinsalu, M., Li, Y., Liang, X., Liu, S., Logroscino, G., Lotufo, P. A., Lu, Y., Ma, J., Mainoo, N. K., Mensah, G. A., Merriman, T. R., Mokdad, A. H., Moschandreas, J., Naghavi, M., Naheed, A., Nand, D., Narayan, K. M. V., Nelson, E. L., Neuhouser, M. L., Nisar, M. I., Ohkubo, T., Oti, S. O., Pedroza, A., Prabhakaran, D., Roy, N., Sampson, U., Seo, H., Sepanlou, S. G., Shibuya, K., Shiri, R., Shiue, I., Singh, G. M., Singh, J. A., Skirbekk, V., Stapelberg, N. J. C., Sturua, L., Sykes, B. L., Tobias, M., Tran, B. X., Trasande, L., Toyoshima, H., van de Vijver, S., Vasankari, T. J., Veerman, J. L., VelasquezMelendez, G., Vlassov, V. V., Vollset, S. E., Vos, T., Wang, C., Wang, X., Weiderpass, E., Werdecker, A., Wright, J. L., Yang, Y. C., Yatsuya, H., Yoon, J., Yoon, S.-J., Zhao, Y., Zhou, M., Zhu, S., Lopez, A. D., Murray, C. J. L. \& Gakidou, E. (2014). Global, regional, and national prevalence of overweight and obesity in children and adults during 1980-2013: A systematic analysis for the Global Burden of Disease Study 2013. The Lancet, 384(9945), 766-781.

Nishita, K. D., Roberts, R. L., Bean, M. M. \& Kennedy, B. M. (1976). Development of a yeastleavened rice-bread formula. Cereal Chemistry, 53(5), 626-635.

Pääkkö, M., Ankerfors, M., Kosonen, H., Nykänen, A., Ahola, S., Österberg, M., Ruokolainen, J., Laine, J., Larsson, P. T., Ikkala, O. \& Lindström, T. (2007). Enzymatic hydrolysis combined with mechanical shearing and high-pressure homogenization for nanoscale cellulose fibrils and strong gels. Biomacromolecules, 8(6), 1934-1941.

Paciulli, M., Rinaldi, M., Cirlini, M., Scazzina, F. \& Chiavaro, E. (2016). Chestnut flour addition in commercial gluten-free bread: A shelf-life study. LWT - Food Science and Technology, 70, 8895 .

Phimolsiripol, Y., Mukprasirt, A. \& Schoenlechner, R. (2012). Quality improvement of rice-based gluten-free bread using different dietary fibre fractions of rice bran. Journal of Cereal Science, 56(2), 389-395.

Ren, Y., Linter, B. R. \& Foster, T. J. (2020). Cellulose fibrillation and interaction with psyllium seed husk heteroxylan. Food Hydrocolloids, 104, 105725. 
Ren, Y., Linter, B. R. \& Foster, T. J. (Unpublished results-a). A comprehensive investigation of gluten free bread dough rheology, proving and baking performance and bread qualities by response surface design and principal component analysis. Manuscript submitted for publication.

Ren, Y., Yakubov, G., Linter, B. R., MacNaughtan, B. \& Foster, T. J. (Unpublished results-b). Temperature fractionation, and physicochemical and rheological analysis of psyllium. Manuscript submitted for publication.

Romano, A., Toraldo, G., Cavella, S. \& Masi, P. (2007). Description of leavening of bread dough with mathematical modelling. Journal of Food Engineering, 83(2), 142-148.

Ronda, F., Pérez-Quirce, S., Angioloni, A. \& Collar, C. (2013). Impact of viscous dietary fibres on the viscoelastic behaviour of gluten-free formulated rice doughs: A fundamental and empirical rheological approach. Food Hydrocolloids, 32(2), 252-262.

Sahlström, S., Park, W. \& Shelton, D. R. (2004). Factors influencing yeast fermentation and the effect of LMW sugars and yeast fermentation on hearth bread quality. Cereal Chemistry, 81(3), 328335.

Sangnark, A. \& Noomhorm, A. (2004). Effect of dietary fiber from sugarcane bagasse and sucrose ester on dough and bread properties. LWT - Food Science and Technology, 37(7), 697-704.

Sapone, A., Bai, J. C., Ciacci, C., Dolinsek, J., Green, P. H., Hadjivassiliou, M., Kaukinen, K., Rostami, K., Sanders, D. S., Schumann, M., Ullrich, R., Villalta, D., Volta, U., Catassi, C. \& Fasano, A. (2012). Spectrum of gluten-related disorders: consensus on new nomenclature and classification. BMC Medicine, 10(1), 1-12.

Scanlon, M. G. \& Zghal, M. C. (2001). Bread properties and crumb structure. Food Research International, 34(10), 841-864.

Schober, T. J., Bean, S. R. \& Boyle, D. L. (2007). Gluten-free sorghum bread improved by sourdough fermentation: Biochemical, rheological, and microstructural background. Journal of Agricultural and Food Chemistry, 55(13), 5137-5146.

Schuppan, D. (2000). Current concepts of celiac disease pathogenesis. Gastroenterology, 119(1), 234242.

Shah, P., Campbell, G. M., McKee, S. L. \& Rielly, C. D. (1998). Proving of bread dough: Modelling the growth of individual bubbles. Food and Bioproducts Processing, 76(2), 73-79.

Shaw, J. E., Sicree, R. A. \& Zimmet, P. Z. (2010). Global estimates of the prevalence of diabetes for 2010 and 2030. Diabetes Research and Clinical Practice, 87(1), 4-14.

Stenstad, P., Andresen, M., Tanem, B. S. \& Stenius, P. (2008). Chemical surface modifications of microfibrillated cellulose. Cellulose, 15(1), 35-45.

Sullo, A. \& Foster, T. J. (2010). Characterisation of starch/cellulose blends. Annual Transactions of the Nordic Rheology Society, 18, 1-7. 
Tanner, R. I., Qi, F. \& Dai, S.-C. (2008). Bread dough rheology and recoil: I. Rheology. Journal of Non-Newtonian Fluid Mechanics, 148(1), 33-40.

Turbak, A. F., Snyder, F. W. \& Sandberg, K. R. (1982). Food products containing microfibrillated cellulose. US4341807.

Turbak, A. F., Snyder, F. W. \& Sandberg, K. R. (1983a). Microfibrillated cellulose. US4374702A.

Turbak, A. F., Snyder, F. W. \& Sandberg, K. R. (1983b). Suspensions containing microfibrillated cellulose. US4378381A.

Upadhyay, R., Ghosal, D. \& Mehra, A. (2012). Characterization of bread dough: Rheological properties and microstructure. Journal of Food Engineering, 109(1), 104-113.

Van Riemsdijk, L. E., van der Goot, A. J., Hamer, R. J. \& Boom, R. M. (2011). Preparation of glutenfree bread using a meso-structured whey protein particle system. Journal of Cereal Science, 53(3), 355-361.

Van Vliet, T., Janssen, A. M., Bloksma, A. H. \& Walstra, P. (1992). Strain hardening of dough as a requirement for gas retention. Journal of Texture Studies, 23(4), 439-460.

Villanueva, M., Harasym, J., Muñoz, J. M. \& Ronda, F. (2019). Rice flour physically modified by microwave radiation improves viscoelastic behavior of doughs and its bread-making performance. Food Hydrocolloids, 90, 472-481.

Wagner, M., Quellec, S., Trystram, G. \& Lucas, T. (2008). MRI evaluation of local expansion in bread crumb during baking. Journal of Cereal Science, 48(1), 213-223.

Wahab, P. J., Meijer, J. W., Goerres, M. S. \& Mulder, C. J. (2002). Coeliac disease: changing views on gluten-sensitive enteropathy. Scandinavian Journal of Gastroenterology, 37(236), 60-65.

Walls, H. J., Caines, S. B., Sanchez, A. M. \& Khan, S. A. (2003). Yield stress and wall slip phenomena in colloidal silica gels. Journal of Rheology, 47(4), 847-868.

Zandonadi, R. P., Botelho, R. B. A. \& Araujo, W. M. C. (2009). Psyllium as a substitute for gluten in bread. Journal of the American Dietetic Association, 109(10), 1781-1784.

Zimmermann, T., Pöhler, E. \& Geiger, T. (2004). Cellulose fibrils for polymer reinforcement. Advanced Engineering Materials, 6(9), 754-761. 